\title{
Waterborne Polyurethane-Acrylic Hybrid Nanoparticles by Miniemulsion Polymerization: Applications in Pressure-Sensitive Adhesives
}

\author{
Aitziber Lopez $z^{\dagger}$, Elise Degrandi-Contraires ${ }^{\ddagger+}$, Elisabetta Canetta ${ }^{\S}{ }^{\|}$, Costantino Creton ${ }^{\ddagger}$, Joseph L. \\ Keddie $^{\S *}$, and José M. Asua ${ }^{\dagger}$
}

'Institute for Polymer Materials (POLYMAT) and Grupo de Ingeniería Química, Dpto. de Química Aplicada, University of the Basque Country, Joxe Mari Korta zentroa, Tolosa Etorbidea 72, 20018 Donostia-San Sebastián, Spain

${ }^{\ddagger}$ Laboratoire de Physico-Chimie des Polymères et Milieux Dispersés, ESPCI, CNRS, 10 Rue Vauquelin, F-75231 Paris Cédex 05, France

${ }^{\S}$ Department of Physics, Faculty of Engineering and Physical Sciences, University of Surrey, Guildford, Surrey GU2 7XH, England, UK

Current address: School of Physics and Astronomy, University of St. Andrews, St. Andrews, Fife KY16 9AJ, Scotland, UK

+ Current address: Laboratoire de Physique des Solides, Université Paris sud, UMR CNRS 8502, Bat. 510, Campus d'Orsay, 91405 Orsay cedex, France

\begin{abstract}
Waterborne polyurethane-acrylic hybrid nanoparticles for application as pressuresensitive adhesives (PSAs) were prepared by a one-step miniemulsion polymerization. The addition of polyurethane into a standard waterborne acrylic formulation results in a large increase of the cohesive strength and hence a much higher shear holding time (greater than seven weeks at room temperature), which is a highly desirable characteristic for PSAs. However, with the increase in cohesion, there is a decrease in the relative viscous component, and hence there is a decrease in the tack energy. The presence of a small concentration of methyl methacrylate (MMA) in the acrylic copolymer led to phase separation within the particles and created a hemispherical morphology. The tack energy was particularly low in the hybrid containing MMA because of the effects of lower energy dissipation and greater crosslinking. These results highlight the great sensitivity of the
\end{abstract}

* Corresponding author. E-mail: j.keddie@surrey.ac.uk. Tel +44-1483-686803; Fax +44-1483686781. 
viscoelastic and adhesive properties to the details of the polymer network architecture and hence to the precise composition and synthesis conditions.

\section{Introduction}

Waterborne polymer-polymer hybrid latexes have attracted a great deal of interest both in academia and in industry owing to the opportunity they bring to develop environmentally-friendly materials that combine the positive properties of both polymers in a synergistic way. Although most of the studies reported in the past have focused on coatings applications, ${ }^{1-15}$ there have been recent reports of hybrid latex particles of acrylic and tackifier in adhesive applications ${ }^{16}$. Polyurethaneacrylic hybrid waterborne nanoparticles, which are the subject of the present work, have been used recently to produce pressure-sensitive adhesives (PSAs) ${ }^{17}$.

PSAs are a distinct type of adhesive that adhere instantly and firmly to a wide variety of surfaces under the application of only light pressure. This type of adhesive has been traditionally synthesized by solution polymerization, but growing environmental restrictions on volatile organic compound (VOC) emissions have forced the PSA industry to adopt the production of waterborne PSAs. Unfortunately, waterborne PSAs often present inferior properties (e.g., water resistance ${ }^{18}$ and tack/shear strength ${ }^{19,20}$ ) in comparison to solvent-based adhesives.

A high shear strength in uncrosslinked polymers is directly related to a high zero-shear-rate viscosity $^{21,}{ }^{22}$, while tackiness can be correlated with a high molecular weight between entanglements $\left(M_{\mathrm{e}}\right)$. Thus, in principle, a very high molecular weight polymer with a high $M_{\mathrm{e}}$ would have a high shear resistance and be highly tacky. This is true to a point: commercial PSAs are invariably partially crosslinked and have no measurable zero-shear-rate viscosity. In this case, the optimization is less straightforward. Recent studies show that the introduction of a percolating crosslinked molecular structure in combination with a high proportion of acrylic pendant chains and a high sol fraction can potentially increase the cohesive strength of an adhesive while maintaining a reasonable tack value ${ }^{23-25}$. The goal of the present study was along these lines. 
The introduction of polyurethane (PU) into a standard waterborne acrylic latex is expected to increase the adhesive shear strength of the resulting film because the polar groups of the polyurethane may form hydrogen bonds with each other. Moreover, because the high flexibility of polyurethane molecular chains leads to a low entanglement molecular weight, a higher density of entanglements is expected.

The blending of colloidal polymer particles is a common approach to create waterborne nanocomposites. However, in most of the cases, incompatibility between the polymers causes their phase separation, hindering the desired synergy of properties in the final product. The creation of covalent bonds between both phases ${ }^{13,26,27}$ can overcome the incompatibility between polyurethane and acrylic polymers. Even though seeded emulsion polymerization has been used to synthesize waterborne hybrid nanoparticles ${ }^{26,27}$, miniemulsion polymerization seems to be the most promising technique for producing them ${ }^{13}$. Because of the predominance of droplet nucleation, miniemulsion polymerization allows the possibility of working with pre-formed hydrophobic polymers. Moreover, step-growth ${ }^{28-30}$ and free-radical polymerizations can be carried out in a miniemulsion process.

In this work, waterborne polyurethane-acrylic hybrid particles, at $50 \mathrm{wt} \%$ solids, for application as PSAs were prepared by a one-step miniemulsion polymerization. All the components of the formulation were mixed together, and both polyaddition and free radical polymerization occurred simultaneously in a semicontinuous process. Polyaddition between a reactive urethane prepolymer (PU) and a functionalized acrylic monomer (hydroxyethyl methacrylate, HEMA) allowed the compatibilization between both polymers. Our experiments investigated the effect of the addition of a small concentration of methyl methacrylate to the copolymer on the resulting particle morphology and properties. The nano-scale structure and mechanical properties, as well as the macro-scale adhesive performance, of the polyurethane/acrylic hybrid adhesives are compared with the equivalent acrylic formulations. 


\section{Materials and Methods}

\subsection{Materials}

The urethane prepolymer (Incorez 701) was supplied by Incorez Ltd. (Preston, England). Incorez 701 is a $100 \%$ solids reactive urethane prepolymer based on an aliphatic isocyanate (IPDI) and a polyether, specially designed for adhesive applications. For simplicity, in the remainder of the paper, the urethane prepolymer will be called PU. According to the manufacturer, the equivalent weight of the prepolymer is 1050 g/equiv., and the NCO concentration is $c a .4 .0$ mole \%. The prepolymer was used without any further purification, and it was directly dissolved in the organic phase.

The monomers, 2-ethylhexyl acrylate (2EHA, Quimidroga), methyl methacrylate (MMA, Quimidroga), methacrylic acid (MAA, Aldrich), hydroxyethyl methacrylate (HEMA, Aldrich) and stearyl acrylate (SA, Aldrich), were likewise used without further purification. Stearyl acrylate is a highly water insoluble monomer that can act as a co-stabilizer to minimize the Oswald ripening effect, thus making unnecessary the use of non-reactive costabilizers, such as hexadecane, that undesirably increase the VOC content of the final latex. Bisphenol A (BPA, Aldrich) was used as a chain extender agent for the urethane prepolymer, and dibutyltin dilaurate (DBTDL, Aldrich) was used as a catalyst for the polyaddition. Alkyl diphenyloxide disulfonate (Dowfax 2A1, Dow Chemical) was the main surfactant in the miniemulsion preparation, and sodium dodecyl sulfate (SDS, Aldrich) was post-added to the miniemulsion in order to improve its stability. Potassium persulfate (KPS, Fluka) was used as the initiator for radical polymerization. Sodium bicarbonate $\left(\mathrm{NaHCO}_{3}\right.$, Fluka) was added to the formulation in order to decrease the viscosity of the miniemulsions. Doubly deionized water (DDI) was used throughout the work.

\subsection{Miniemulsification}


The organic phase was prepared by dissolving the urethane prepolymer, the chain extender (Bisphenol A) and the polyaddition catalyst (DBTL) in the acrylic monomer mixture of 2EHA+MMA/MAA/HEMA/SA in relative concentrations of 95.19/0.96/0.96/3.85 wt.\%.

The aqueous phase was prepared by dissolving the surfactant (Dowfax 2A1) and the salt $\left(\mathrm{NaHCO}_{3}\right)$ in DDI water. Both phases were mixed for 15 minutes using a magnetic stirrer at $700 \mathrm{rpm}$ agitation. For the standard acrylic system, the coarse emulsion was first sonified for 15 minutes (9 output control, $80 \%$ duty cycle) in a Branson Sonifier 450 and then homogenized in a two-valve, high-pressure homogenizer (Laboratory 60.10 Manton-Gaulin) by passing four cycles at $41 \mathrm{MPa}$ in the first valve and $4 \mathrm{MPa}$ in the second valve. The homogenizer was arranged in a loop. One cycle was defined as the time needed to pass the volume of the storage tank once through the homogenizer. Hybrid miniemulsion formulations were prepared by sonication, without introducing the coarse emulsion into the high pressure homogenizer. Typical formulations used for preparing the standard acrylic and hybrid miniemulsions are presented in Table 1.

Table 1. Typical formulations for miniemulsion preparation

\begin{tabular}{|c|c|c|c|c|}
\hline \multicolumn{3}{|c|}{ Standard acrylic } & \multicolumn{2}{|c|}{ Hybrid } \\
\hline Ingredient & Amount (g) & wt.\% & Amount (g) & wt.\% \\
\hline 2EHA & 441.40 or 436.5 & 94.23 or $93.27^{\text {a) }}$ & 396.9 or 392.8 & 94.23 or $93.27^{\mathrm{a})}$ \\
\hline MMA & 0 or 4.5 & 0 or $0.96^{\mathrm{a})}$ & 0 or 4.5 & 0 or $0.96^{a)}$ \\
\hline MAA & 4.5 & $0.96^{\text {a) }}$ & 4.5 & $0.96^{\text {a) }}$ \\
\hline HEMA & 4.5 & $0.96^{\mathrm{a})}$ & 4.5 & $0.96^{\text {a) }}$ \\
\hline SA & 18.0 & $3.85^{\text {a) }}$ & 16.2 & $3.85^{\text {a) }}$ \\
\hline Incorez 701 & - & - & 45 & $9.65^{b)}$ \\
\hline Bisphenol A & - & - & 6.12 & $\begin{array}{c}\text { Amount for having } \\
\mathrm{OH} / \mathrm{NCO}=2\end{array}$ \\
\hline DBTDL & - & - & 0.23 & $500 \mathrm{ppm}^{\mathrm{c})}$ \\
\hline Dowfax 2A1 & 20.7 & $1.92^{\text {a) }}$ & 18.0 & $1.92 \%{ }^{a)}$ \\
\hline $\mathrm{NaHCO}_{3}$ & 0.74 & $0.02 \mathrm{M}^{\mathrm{d})}$ & 0.74 & $0.02 \mathrm{M}^{\mathrm{d})}$ \\
\hline
\end{tabular}


DDI water 350

a) Weight based on monomer weight (wbm)

b) Weight based on organic phase weight (wbo)

c) ppm based on organic phase

d) Based on water phase

After miniemulsification, $0.87 \mathrm{wt} \%$ (weight based on organic phase) of sodium dodecyl sulfate (as a $6.5 \mathrm{wt} \%$ solution of SDS in DDI water) was added to the dispersion in order to increase its colloidal stability.

\subsection{Polymerization Process}

Semicontinuous processes were carried out in a 750-ml glass, jacketed reactor equipped with a reflux condenser, sampling device, $\mathrm{N}_{2}$ inlet, two feeding inlets and a stainless steel anchor type stirrer rotating at $250 \mathrm{rpm}$.

During the polymerization process, $20 \mathrm{wt} . \%$ of the miniemulsion (52 wt.\% organic phase) was first placed into the reactor and allowed to polymerize over 1 hour by adding $0.5 \mathrm{wt} \%$ (wbm) of initiator (KPS). The rest of the miniemulsion and the initiator solution were then fed for 3 hours. After the end of the feeding period, the polymerization was allowed to occur in batch for 2 hours. The reaction temperature was $80{ }^{\circ} \mathrm{C}$. Samples were withdrawn at regular intervals, and the polymerization was short-stopped with hydroquinone, to enable analysis of the conversion over time. The final solids content of the latexes was about $50 \mathrm{wt} . \%$, and the final PU concentration in the hybrid was 9.65 wt.\% with respect to the organic phase.

\subsection{Particle and Polymer Characterization}

Z-average diameters of the miniemulsion droplets and polymer particles were measured by dynamic light scattering (Zetasizer Nano Z, Malvern Instruments). Samples were prepared by 
Published in Langmuir (2011) 27(7) pp 3878-3888

diluting a fraction of the latex or miniemulsion with deionized water (saturated with monomer in the case of miniemulsion droplet measurements). The numbers of particles $\left(N_{\mathrm{p}}\right)$ and droplets $\left(N_{\mathrm{d}}\right)$ were calculated from the light scattering average diameters; as a consequence they contain some uncertainty.

Miniemulsion stability was measured by recording the backscattering signal of the dispersion (TurbiscanLAB equipment) at $30{ }^{\circ} \mathrm{C}$ every 30 minutes for five hr. The evolution of the backscattering signal over time $(\mathrm{d}(\mathrm{B}) / \mathrm{dt})$ gives an indication of the miniemulsion stability: a lower change in the backscattering signal over time, indicates a more stable miniemulsion.

Conversion was determined gravimetrically, and it was calculated with respect to the monomer. The amount of PU was not taken into account in the calculation. The overall conversion, $X_{0}$, was defined as the weight ratio between the acrylic polymer and the total amount of acrylic monomer in the formulation.

The gel content was measured gravimetrically as follows. First, the latexes were coagulated at 60 ${ }^{\circ} \mathrm{C}$ using a $\mathrm{CaCl}_{2}$ aqueous solution $\left(2 \mathrm{wt} \% \mathrm{CaCl}_{2}\right)$ and the coagulum was dried in a ventilated oven at $60{ }^{\circ} \mathrm{C}$ for two days. Then, a metallic grid was first weighed $\left(W_{1}\right)$ and placed in a Soxhlet system in which THF was maintained under reflux for 1 hour. The humidified grid was then weighed $\left(W_{2}\right)$ and dried in a ventilated oven at $60{ }^{\circ} \mathrm{C}$ for 3 hours. About $0.5 \mathrm{~g}$ of coagulum was then placed in the metallic grid $\left(W_{3}\right)$ and a continuous extraction with tetrahydrofuran (THF) under reflux in the Soxhlet for 24 hours was carried out. The extraction time was chosen to be long enough to ensure a constant measured value of the gel fraction. In other words, the sol fraction extracted in each experiment was the maximum that could be extracted under the conditions used. Thin films were used to minimize the risk of sol molecules being trapped in the gel network. The humidified grid and the swollen gel were then weighed $\left(W_{4}\right)$, and dried in a ventilated oven at $60{ }^{\circ} \mathrm{C}$ overnight. Finally, the dried metallic grid and the gel polymer were again weighed $\left(W_{5}\right)$.

The gel content was defined as 


$$
\text { Gel content } w t \%=\frac{\left(W_{5}-W_{1}\right)}{\left(W_{3}-W_{1}\right)} 100
$$

The swelling capability, $Q$, was calculated as

$$
\text { Swelling capability }=\frac{\left(W_{4}-W_{2}\right)}{\left(W_{5}-W_{1}\right)}
$$

The sol molecular weight distribution was measured by size exclusion chromatography. The set-up consisted of a pump (Waters 510), an auto-sampler (Waters 717), a differential refractometer (Waters 2410) and three columns in series (Styragel HR2, HR4 and HR6; with pore sizes ranging from $10^{2}$ to $10^{6} \AA$ ). The analysis was performed at $35^{\circ} \mathrm{C}$, and THF was used as the solvent in a flow rate of $1 \mathrm{~mL} \mathrm{~min}^{-1}$. The equipment was calibrated using polystyrene (PS) standards, and the relative molecular weights (according to the PS reference) were calculated.

\subsection{Atomic Force Microscopy}

The nano-structural and nano-mechanical properties of the PSA films were determined by using an atomic force microscope (AFM) (NTEGRA NT-MDT, Moscow, Russia) in imaging and force mapping modes, respectively. Individual latex particles were imaged in the semi-contact mode. Latexes were diluted 100 times in deionised water and then spin-coated at $4000 \mathrm{rpm}$ onto $1 \mathrm{~cm} \times 1$ $\mathrm{cm}$ sheets of freshly-cleaved mica. Silicon cantilevers (ATEC-NC, Nanosensors, Switzerland) with a nominal spring constant of $k=45 \mathrm{~N} / \mathrm{m}$ and a high resonance frequency $(330 \mathrm{kHz})$ were used. All the AFM experiments were performed in air at room temperature, and the height and phase images (scan sizes ranging from $10 \mu \mathrm{m} \times 10 \mu \mathrm{m}$ to $2 \mu \mathrm{m} \times 2 \mu \mathrm{m}$ and 256 x 256 pixels) were acquired using a scan rate of $1.56 \mathrm{~Hz}$.

The surfaces were scanned by an ultrasharp silicon tip with a radius of curvature $<10 \mathrm{~nm}$ microfabricated on the cantilever, and moved by a piezoelectric translator. The interaction force, $F$, between the tip and the sample was directly obtained from the cantilever deflection using Hooke's law $(F=k z$, where $z$ is the cantilever deflection in the vertical direction). The set of $z=\mathrm{f}(x, y)$ 
provided the surface topography (i.e., height image). A phase image was generated simultaneously by mapping the relative phase angle between the driving oscillation amplitude and the cantilever deflection recorded by the photodiode. The phase image provides information on the energy dissipation between the tip and the surface ${ }^{31}$. When the AFM tip encounters a region with a greater viscous component of the viscoelasticity, more energy is dissipated ${ }^{32}$, and the region appears darker in the phase image. On the contrary, when the viscous component is lower, less energy is dissipated and the region appears bright in the phase image ${ }^{33}$. The free amplitude, $A_{0}$ (i.e., amplitude of the oscillation of the cantilever in air) was used as input for a feedback circuitry that allowed the tip to be maintained at a constant $z$ from the surface (constant amplitude imaging mode). The oscillation amplitude of the AFM cantilever was kept just below $A_{0}$, which was typically $295 \mathrm{~nm}$. The set-point amplitude, $A_{\mathrm{sp}}$ (i.e., amplitude of the oscillation when the tip is in contact with the sample surface) was kept just below $A_{0}$, in order to image the PSA with "soft-tapping" conditions. These tapping conditions minimized the AFM tip indentation depth and thus reduced image artefacts ${ }^{34}$.

\subsection{Macro-scale Experiments}

Shear resistance was measured by performing the holding power shear test ${ }^{35}$. Films were cast using a $120 \mu \mathrm{m}$ square applicator onto plasma-treated PP. Films were dried in an oven at $60{ }^{\circ} \mathrm{C}$ for 20 minutes and then held for 20 minutes at $23^{\circ} \mathrm{C}$ and $55 \%$ humidity. The test consists of applying a standard weight $(1 \mathrm{~kg})$ in shear to a standard area of a tape $(2.5 \mathrm{~cm} \times 2.5 \mathrm{~cm})$ attached to a substrate until failure. The time between the application of the load and the separation of the tape is a measurement of the shear strength. Kraft paper was used as testing substrate.

Adhesion measurements were performed using a custom-designed probe-tack set-up ${ }^{36}$. Latexes were cast on a microscope glass slide by using a square applicator and dried for $48 \mathrm{~h}$ at room temperature followed by 1 minute of drying at $110^{\circ} \mathrm{C}$. The final thickness $(h)$ of the film was about $100 \mu \mathrm{m}$. In the probe-tack tests carried out, a probe comes in contact with the film at a given velocity 
of $30 \mu \mathrm{m} \mathrm{s}^{-1}$ (Figure 1a). A $1 \mathrm{MPa}$ compressive pressure is applied for 1 second (Figure 1b) and the probe is removed from the film at a controlled velocity, $V_{\mathrm{deb}}$, of $100 \mu \mathrm{m} \mathrm{s}^{-1}$ (Figure 1c), which corresponds to an initial debonding rate (defined as $V_{\mathrm{deb}} / h$ ) of $1 \mathrm{~s}^{-1}$. The debonding force and displacement were recorded and then converted to nominal stress $\sigma$ and strain $\varepsilon$ by normalizing the force by the initial contact area and the displacement by the initial thickness of the film, respectively. The debonding mechanisms were observed with a video camera.

(a)

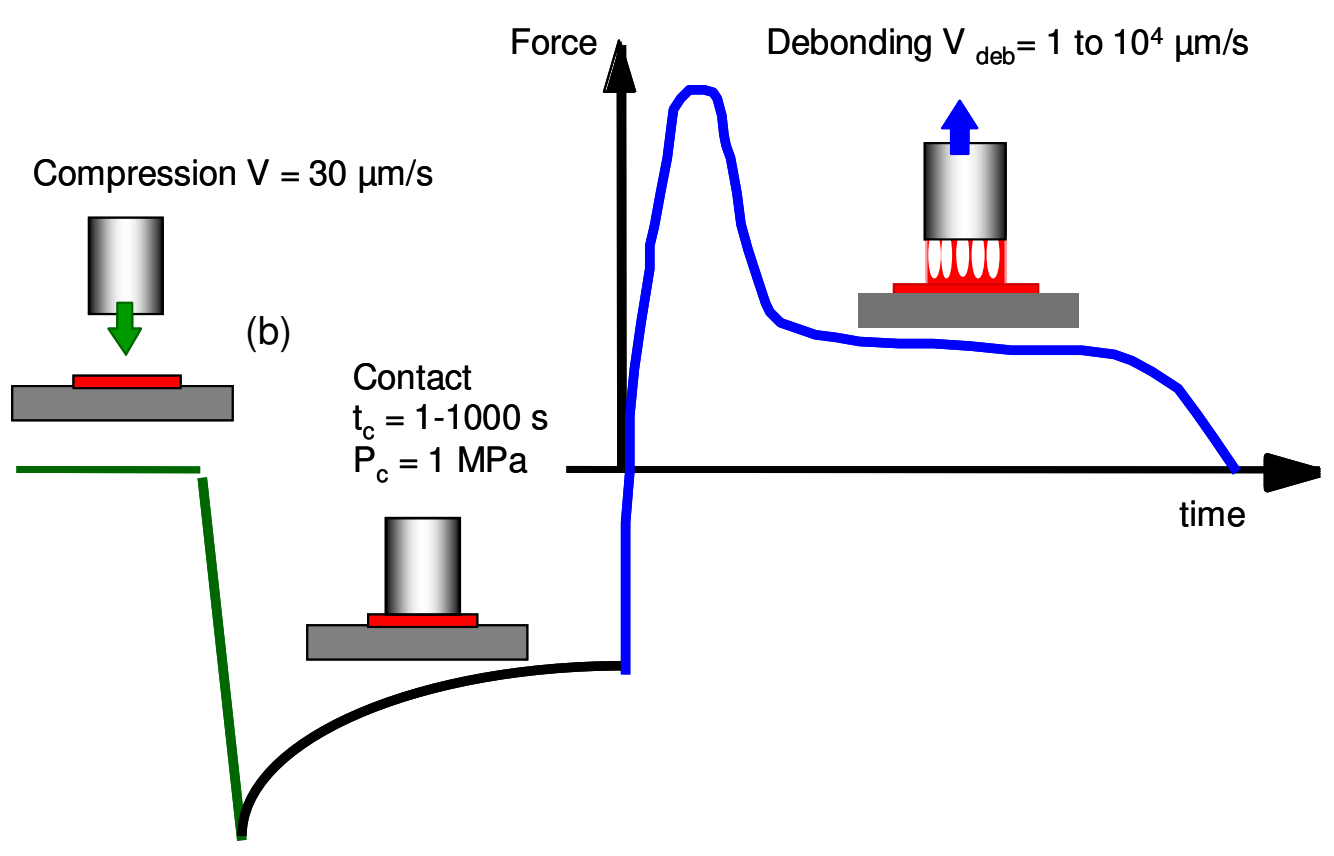

Figure 1. Schematic diagram of a probe tack test and typical values of the main parameters

The analysis of both the curves $\sigma=f(\varepsilon)$ and the videos provides information to evaluate the adhesive properties of the sample. Three important parameters can be typically drawn from the tack curve $^{36-38}$ the maximum stress, corresponding to the onset of cavitation; the maximum deformation at failure, $\left(\varepsilon_{\max }\right)$, corresponding to the maximum elongation of the fibrils; and the stress value in the plateau region $\left(\sigma_{\mathrm{p}}\right)$, which is directly linked to the elasticity of the sample. In this study we are 
mostly interested in comparing the extensibility of the fibrils $\left(\varepsilon_{\max }\right)$ and the tack adhesion energy ( $\left.W_{\mathrm{adh}}\right)$, which is proportional to the area under the stress-strain curve and hence is a function of $\varepsilon_{\max }$ and $\sigma_{\mathrm{p}}$. Multiple measurements were performed for each material to ensure reproducibility, and representative stress-strain curves are presented.

The linear viscoelastic properties of the adhesive layers were carried out with a standard fixed displacement rheometer (RDAII from TA Instrument) in a parallel-plate geometry and a diameter of $8 \mathrm{~mm}$. Thick films of $0.5 \mathrm{~mm}$ were cast in silicone moulds and left to dry at room temperature for 1 week followed by 5 minutes drying at $110^{\circ} \mathrm{C}$. Circular samples of $8 \mathrm{~mm}$ diameter were cut from the films. Experiments were performed at $30{ }^{\circ} \mathrm{C}$ and a deformation of $8 \%$ was imposed on the samples to remain in the linear strain regime.

\subsection{AFM force spectroscopy}

The nano-mechanical properties of PSA films were determined by AFM force spectroscopy (FS) experiments performed in contact mode at room temperature. Films were cast onto polypropylene sheets $(30 \mathrm{~cm}$ x $20 \mathrm{~cm}$ in area) using a $10 \mu \mathrm{m}$ hand-held spiral bar coater. The films were dried at $110{ }^{\circ} \mathrm{C}$ for $3 \mathrm{~min}$. under static air and analysed within $24 \mathrm{~h}$. The thickness of the dried films is estimated to be $5 \mu \mathrm{m}$. Prior to AFM analysis, the film surfaces were rinsed with de-ionized water to remove the excess surfactant. To prepare the samples, $1 \mathrm{~cm} \mathrm{x} 1 \mathrm{~cm}$ pieces were cut from the cast films and mounted on the AFM sample holder.

In the FS experiments, a grid of $20 \times 20$ points on a $2 \mu \mathrm{m} \times 2 \mu \mathrm{m}$ area of the cast PSA was chosen to give a final map of 400 points. $\mathrm{Si}_{3} \mathrm{~N}_{4}$ cantilevers (CSG10, NT-MDT, Moscow, Russia) with a nominal spring constant of $0.1 \mathrm{~N} / \mathrm{m}$ and a nominal resonant frequency of $20 \mathrm{kHz}$ were used. The sharp $\mathrm{Si}_{3} \mathrm{~N}_{4}$ tip (radius of curvature $<10 \mathrm{~nm}$ ) micro-fabricated on the cantilever was brought into contact with the PSA surface. An average normal force of $5 \mathrm{nN}$ was applied by the AFM cantilever onto the sample surface. The sample was then lowered away from the tip at a speed of $0.45 \mu \mathrm{m} / \mathrm{sec}$, 
and a force spectroscopy (FS) curve was recorded (Figure 2a). Before the tip comes into contact with the surface, $F=0$. At a close distance of the tip from the surface, attractive forces act on the tip, and it "jumps" into contact. The force pulling down on the tip is recorded as negative. As the surface is raised upwards, the tip indents into the surface, and the force on the tip becomes positive. The tip is pressed into the surface to a maximum indentation depth to finish the trace. In the retrace, the sample is lowered away from the tip, and a force (defined as negative) pulls down on the tip. The force pulling on the tip, which is related to the force required to strain and "draw" the material in contact with the tip, reaches a maximum. Then the tip detaches from the surface, and the force falls back to zero.

FS curves were recorded at each point of the grid for a total of 400 in each experiment to provide a data set with statistical significance. Force spectroscopy experiments on individual latex particles ${ }^{39}$ and adhesive films ${ }^{16,40-45}$ to determine their nanomechanical properties have already been reported elsewhere.

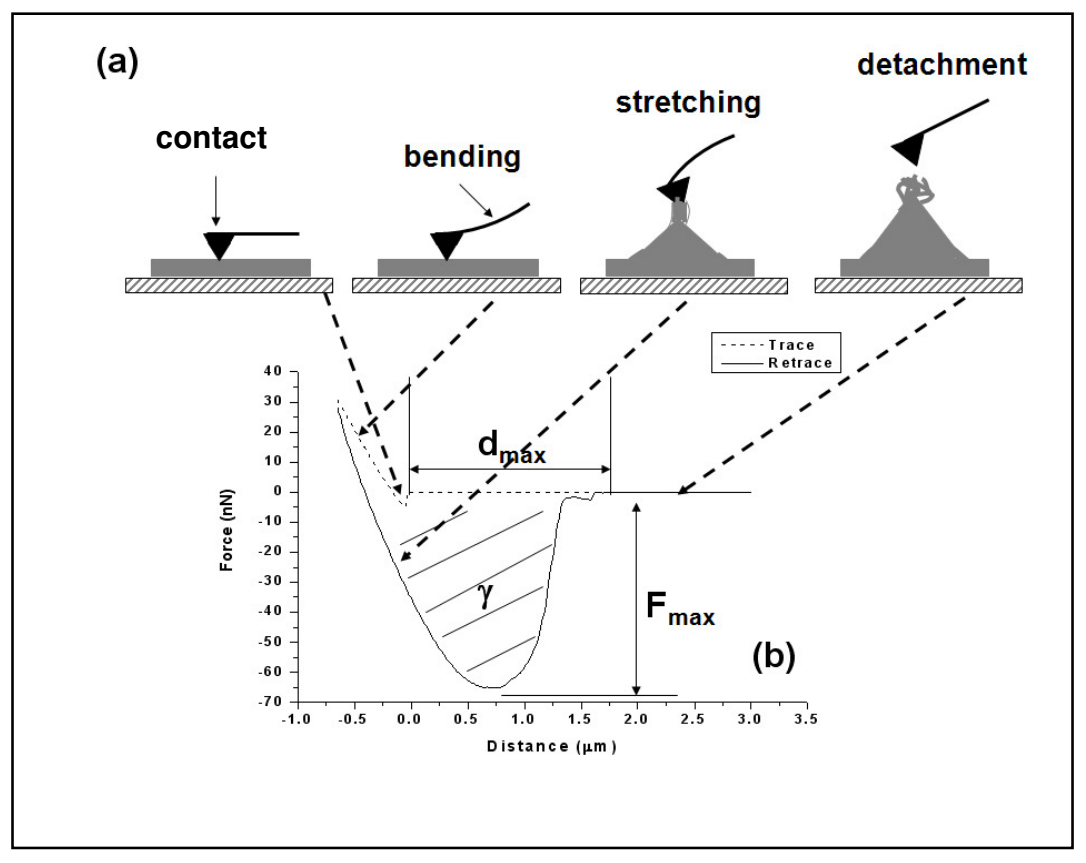

Figure 2. (a) Sketch of the stages of a force spectroscopy experiment. Tip/surface contact and cantilever bending with tip indentation occurs during the trace. On the re-trace, the polymer surface 
is stretched until the point of detachment. (b) Experimental $F-d$ curves for a trace and re-retrace; the stages are identified by the arrows. The meanings of $F_{\max }, d_{\max }$, and $\gamma$ are also identified.

The FS curves were then transformed into force-distance $(F-d)$ curves. The true distance, $d$, between the surface and the AFM tip was calculated by subtracting the deflection of the cantilever, $z$, from the height values that corresponded to the measured piezoelectric displacement, $z_{\text {piezo }}$ :

$$
d=z_{\text {piezo }}-z
$$

\subsection{Nanomechanical properties}

In each $F$ - $d$ curve, the maximum adhesive force of the film surface to the tip $\left(F_{\max }\right)$, the maximum distance of deformation $\left(d_{\max }\right)$ measured from the initial surface position, and the adhesion energy $(\gamma)$, corresponding to the area under the $F$ - $d$ curve, were determined (Figure $2 b$ ). Although $F_{\max }$ is affected by the adhesive forces between the tip and a surface, it is primarily a measure of the force required to deform the polymer in the vicinity of tip's contact area. A histogram and the mean values were acquired for each parameter.

\section{Results and Discussion}

\subsection{Latex Polymerization and Characteristics}

Table 2 presents a summary of the four latexes that were polymerized and that form the basis of this research. The acrylic monomer mixture, PU amount, the miniemulsion droplet size $\left(d_{\mathrm{d}}\right)$, the final particle size $\left(d_{\mathrm{p}}\right)$, and the acrylic monomer conversion $\left(X_{\mathrm{o}}\right)$ are listed. The prefix in the latex name contains information about whether it is a standard acrylic latex $(\mathrm{S})$ or a hybrid latex $(\mathrm{H})$. The final digit indicates whether the MMA concentration is nominally $0.96 \mathrm{wt} . \%$ or $0 \mathrm{wt} . \%$.

Table 2. Series of Latexes Studied and their Characteristics 


\begin{tabular}{|c|c|c|c|c|c|c|c|}
\hline $\begin{array}{l}\text { Latex } \\
\text { name }\end{array}$ & Acrylic formulation (wt. \%) & $\begin{array}{c}\mathrm{PU} \\
(\mathrm{wt} . \%)\end{array}$ & $\begin{array}{c}d_{\mathrm{d}} \\
(\mathrm{nm})\end{array}$ & $\begin{array}{c}d_{\mathrm{p}} \\
(\mathrm{nm})\end{array}$ & $\begin{array}{c}X_{0} \\
(\mathrm{wt} \%)\end{array}$ & $\begin{array}{l}\text { Gel } \\
\text { content } \\
(\text { wt. \%) }\end{array}$ & $\begin{array}{c}\text { Swelling } \\
\text { capability, } \\
Q\end{array}$ \\
\hline S-MMA0 & $\begin{array}{c}94.23 / 0.96 / 0.96 / 3.85 \\
\text { 2EHA/MAA/HEMA/SA }\end{array}$ & 0 & 192 & 194 & 96 & $71.6 \pm 1.1$ & $23.6 \pm 3.7$ \\
\hline S-MMA1 & $\begin{array}{c}\text { 93.27/0.96/0.96/0.96/3.85 } \\
\text { 2EHA/MMA/MAA/HEMA/ } \\
\text { SA }\end{array}$ & 0 & 180 & 198 & 96 & $72.4 \pm 1.7$ & $24.6 \pm 0.6$ \\
\hline H-MMA0 & $\begin{array}{c}\text { 94.23/0.96/0.96/3.85 } \\
\text { 2EHA/MAA/HEMA/SA }\end{array}$ & 9.65 & 189 & 181 & 97 & $79.9 \pm 3.9$ & $19.8 \pm 0.7$ \\
\hline H-MMA1 & $\begin{array}{c}\text { 93.27/0.96/0.96/0.96/3.85 } \\
\text { 2EHA/MMA/MAA/HEMA/ } \\
\text { SA }\end{array}$ & 9.65 & 198 & 172 & 99 & $74.5 \pm 1.7$ & $22.0 \pm 1.4$ \\
\hline
\end{tabular}

It was previously demonstrated ${ }^{46}$ that the addition of reactive PU into the acrylic formulations did not affect the miniemulsion droplet size. Unlike what has been reported for other hybrid systems ${ }^{1,47-}$ ${ }^{52}$, no limiting conversion of the acrylic monomers was observed here when PU was added into the acrylic formulations. During the polymerization, the instantaneous conversion of the acrylic monomers was between 85 and $93 \%$ for the standard acrylic formulations and between 70 and $80 \%$ for the hybrid formulations. The conversion reached values higher than $95 \%$ after the first hour of cooking. The lower instantaneous conversion of the hybrid formulations was attributed to the radical scavenger character of bisphenol $\mathrm{A}^{53,54}$.

The evolution of the gel content as a function of the acrylic overall conversion is presented in Figure 3. Final values are presented in Table 2. The polymerization of acrylic monomers (in the present case, 2-EHA) yields a gel due to the chain transfer to the polymer coupled by termination via combination $^{55}$. The gel fraction in the PU-acrylic hybrid is even higher than in the standard acrylic. Because it has been previously demonstrated that bisphenol A suffers chain transfer in the free radical polymerization of acrylic monomers ${ }^{53,54,56}$, it is expected that the gel formed in the presence of isocyanate-terminated PU is formed by relatively short acrylic chains linked by PU chains. The 
swelling capability is an indirect measurement of the crosslinking density; more densely crosslinked networks will swell to a lesser extent than a less dense network. The data in Table 2 indicate that the hybrid systems had a slightly more densely crosslinked network than the standard acrylic systems. A representative drawing of these gel networks is presented in Figure 4. Of course, the gel network coexists with the sol molecules within each miniemulsion particle, and the sol, in turn, is composed of both free and grafted acrylic and PU chains. The incorporation of the PU occurred from the beginning of the polymerization, as is shown by the high gel content observed even at low acrylic monomer conversion $(<0.3)$.

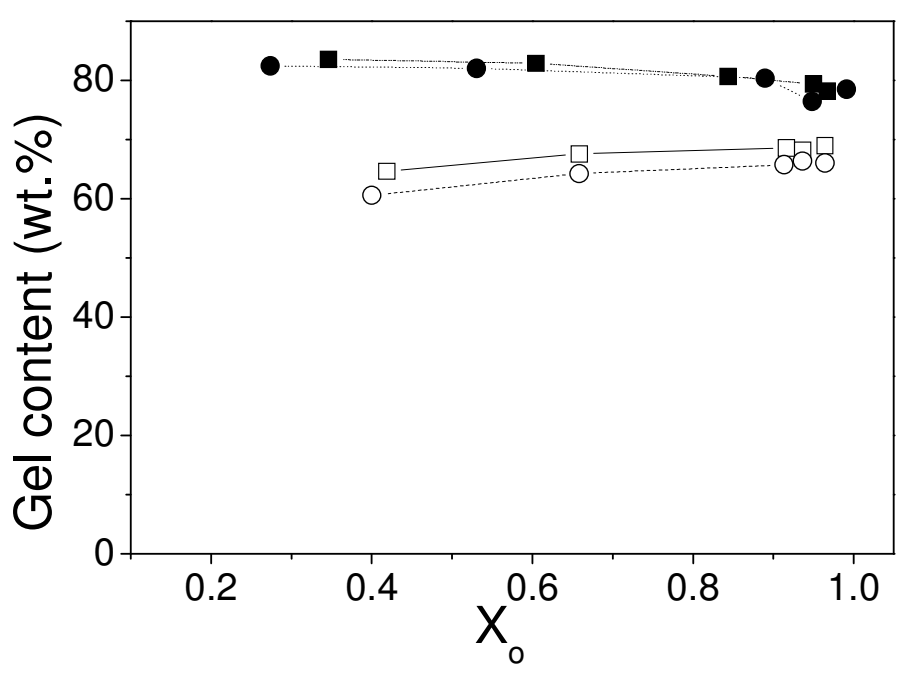

Figure 3. Evolution of the gel content as a function of the acrylic monomers overall conversion.

S-MMA0; ○ S-MMA1; $\square$ H-MMA0; H-MMA1.

(a)

(b) 

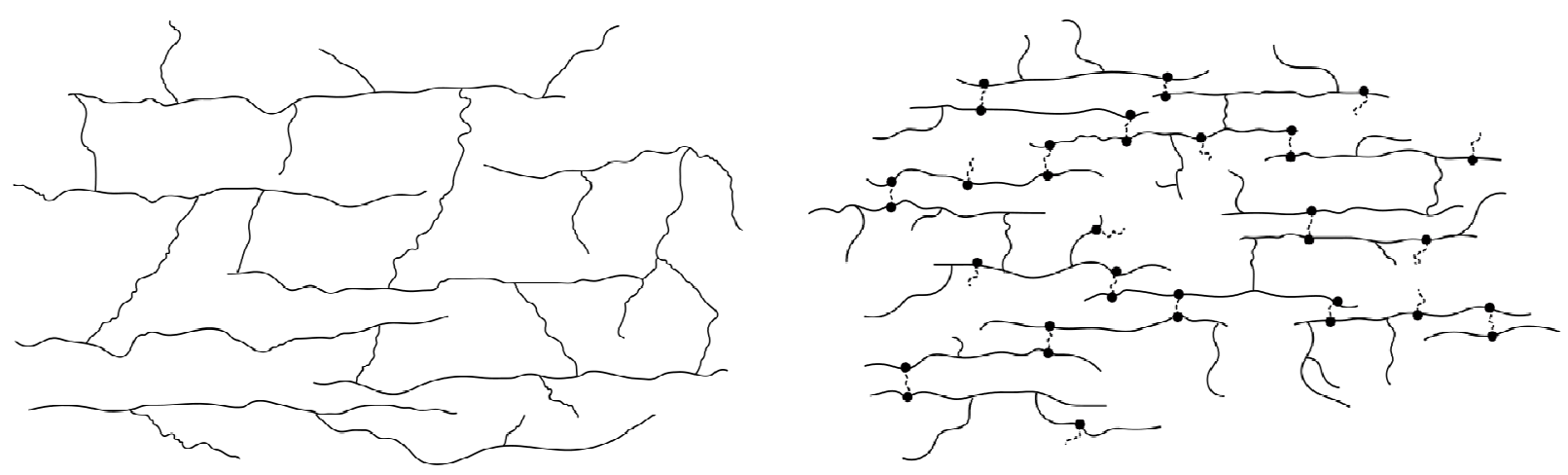

Figure 4. Representation of the gel networks of (a) all acrylic and (b) PU/acrylic hybrid latexes. Solid lines represent acrylic chains and dashed lines represent PU chains. HEMA units (shown as black circles) provide the link between the PU and acrylic chains. Sol molecules are not shown.

The sol molecular weight distributions of the final latexes are presented in Figure 5. No significant differences are observed between the four latexes. This observation is attributed to the similar gel fractions and to the fact that the final sol was determined by the fraction of polymer that was not incorporated within the gel fraction. In free radical polymerization, intermolecular chain transfer to a polymer is proportional to the chain length; hence, the longer chains are preferentially incorporated into the gel fraction of the polymer. The contribution of the PU to the increase in the gel content of the hybrids follows a similar trend, as the linking points are the HEMA molecules, which are expected to be randomly incorporated into the acrylic backbone. Therefore, the longer the chain, the higher that the number of crosslinking points per chain is, then the more likely it is that the chain becomes part of the gel. 


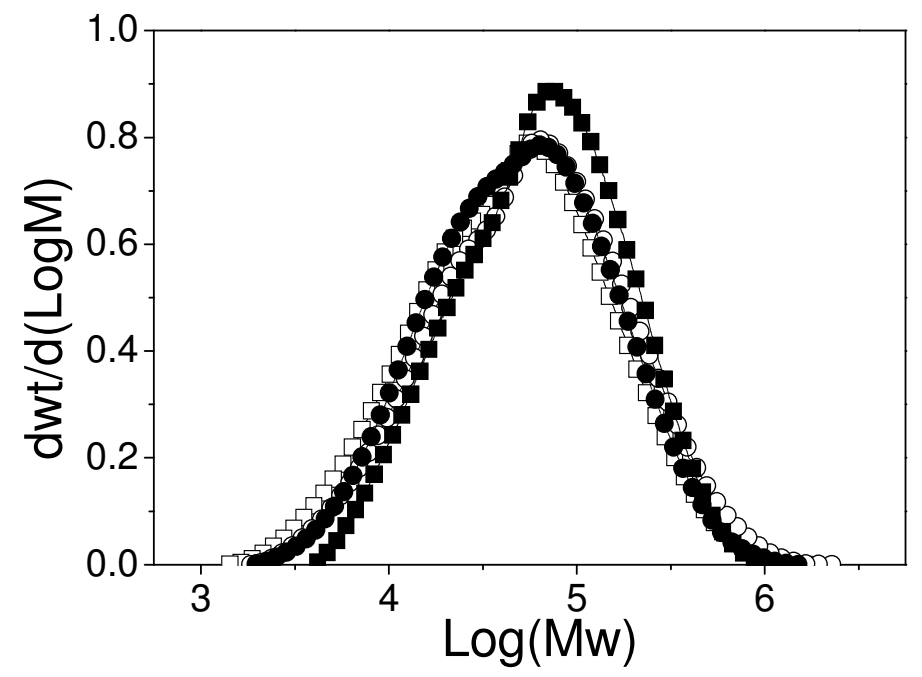

Figure 5. Final sol molecular weight distributions (with respect to standard PS) for the four latexes: S-MMA0; O S-MMA1; $\mathbf{\square}$ H-MMA0; H-MMA1.

\subsection{Particle Morphology}

AFM images of individual particles of the hybrid latexes are presented in Figure 6 for the latex without any MMA (H-MMA0). Because they are soft (i.e. at temperatures well above their glass transition temperature), the particles spread on the mica substrate, as is indicated by their contact diameter being greater than the diameter in the dispersion $(181 \mathrm{~nm})$. The particles maintain their identity, and the extent of their spreading is limited by the presence of the gel network. A theoretical model in the literature has shown that even when it is favorable for a particle to fully wet a substrate according to the spreading coefficient, the contact angle is non-zero because of its elasticity ${ }^{57}$.

The phase images in Figure 6 show a relatively minor contrast within the H-MMA0 particles, which indicates that the viscoelastic properties are broadly uniform. The footprint of the particles, such as in Figure 6c, is not perfectly circular, however, perhaps because of heterogeneities in the particle surface energy. The phase contrast at the particle peripheries is attributed to greater AFM tip interaction with the mica substrates. Near the particle edges, the height image shows that the thickness is lower, so that the phase shift is likely to be caused by the substrate. This homogeneous 
particle structure can be contrasted to the heterogeneous structure found in the latex particles containing MMA (H-MMA1), which is presented in Figure 7.
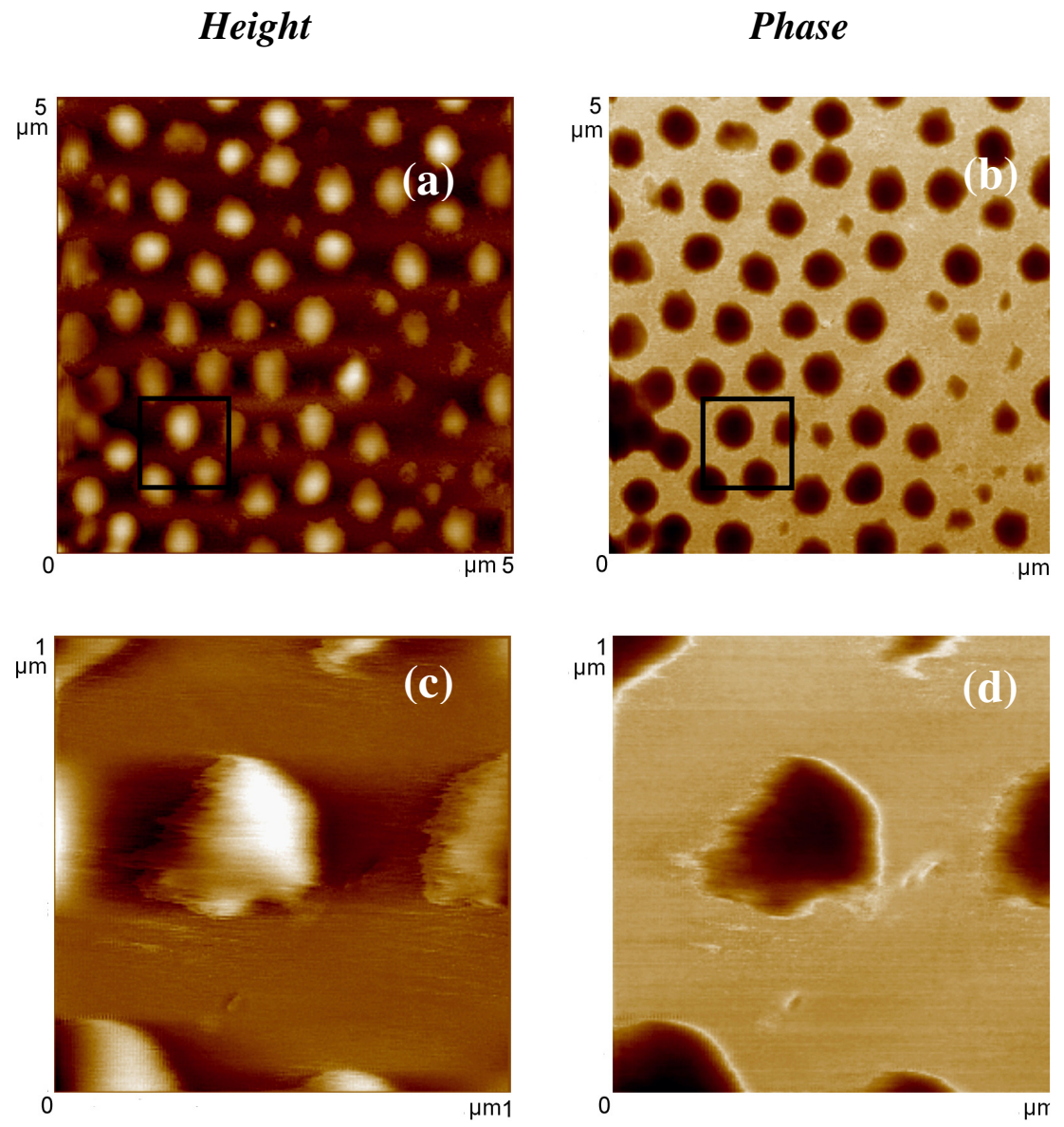

Figure 6. AFM images of individual particles of the hybrid latex without MMA (H-MMA0) on a mica substrate. (a) Height image $(0-35 \mathrm{~nm}$ range $)$ and (b) phase image $\left(0^{\circ}-12^{\circ}\right.$ range $)$ are shown for a $5 \mu \mathrm{m} \times 5 \mu \mathrm{m}$ area. Higher-resolution views of the zones marked in squares are shown in the (c) height $(0-25 \mathrm{~nm})$ and $(\mathrm{d})$ phase $\left(0^{\circ}-10^{\circ}\right)$ images obtained from a $1 \mu \mathrm{m} \times 1 \mu \mathrm{m}$ area. 

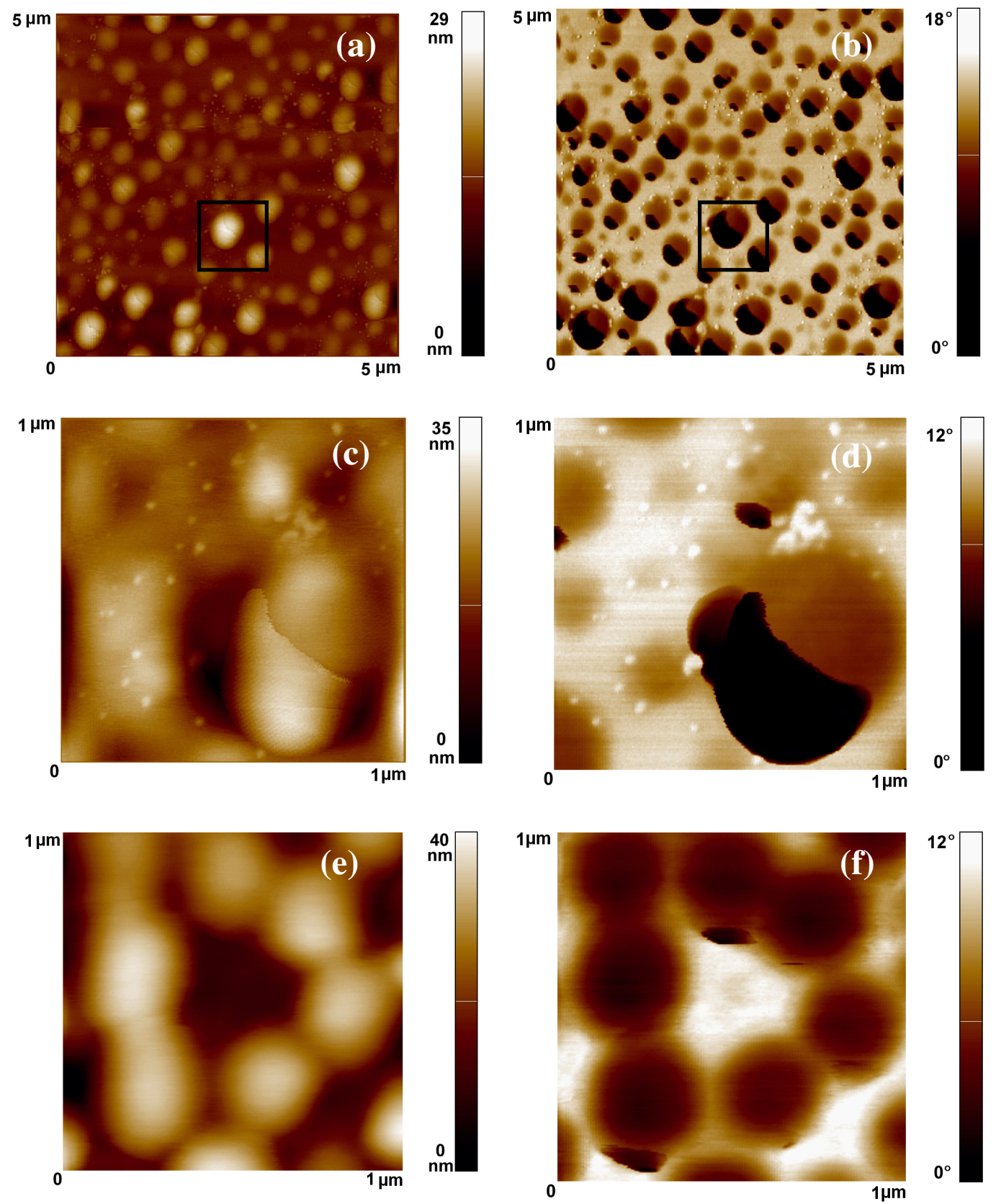

Figure 7. AFM images of individual particles of the hybrid latex containing MMA (H-MMA1) on a mica substrate. (a) Height image and (b) phase image are shown for a $5 \mu \mathrm{m} \times 5 \mu \mathrm{m}$ area. The zone shown with the squares are presented in higher-resolution $(1 \mu \mathrm{m} \times 1 \mu \mathrm{m})$ in a (c) height image and (d) phase image. Another example of particle clusters in the same latex is also shown: (e) height image and (f) phase image $(1 \mu \mathrm{m} \times 1 \mu \mathrm{m}$ area).

An overview of several H-MMA1 particles shows that most contain two distinct components. The phase image in Figure $7 \mathrm{~b}$ reveals that a significant fraction of the H-MMA1 particles contain a 
component that is more dissipative of energy and hence appears darker. Some particles within the population, usually the smaller ones, are homogeneous and only present one component in the phase image. The image shows that the dissipative component tends to appear consistently on one side of the particles. This orientation remained in the images if the scan direction was changed, and the particular direction of orientation varied from one sample to another, thus ruling out scanning artifacts. We attribute this apparent particle orientation to one component adhering to the mica surface and then a tilt in the particle being introduced by the shear forces introduced during the spincasting process.

A higher resolution image (Figures $7 \mathrm{c}$ and $7 \mathrm{~d}$ ) shows a lobed particle in which the two components are clearly separated; that is, the particle presents phase separation. One of the components in the particle (appearing higher than the other component in Figure 7c) encapsulates the other component within the lobed particle. The uncertain effect of the sample preparation and particle deposition by spin-casting on the observed morphology makes it difficult to draw conclusions about the relative hydrophilicity of the two phases. If the morphologies of the waterborne particles were preserved during the sample preparation, then the dark phase would correspond to the more hydrophilic phase, as it is at the particle surface. However, if the morphology is determined by the conditions under which the particles are observed (in the dry state), then the dark phase should be the phase presenting the lower surface energy. In general for polymers, a lower energy surface in air corresponds to more hydrophobic polymers ${ }^{58}$, although some hydrophobic polymers presenting a high surface energy are known (e.g. polystyrene).

In the corresponding phase image (Figure 7d), the outer component is more dissipative of energy, making it appear darker than the component being encapsulated ${ }^{16}$. Combining information from the images, we conclude that a more viscous component (i.e. with a higher loss modulus ${ }^{31,32}$ ) is encapsulating a more elastic core component. 
A possible explanation for the particle structure follows. Comparison between Figures 6 and 7 shows that the addition of a relatively small fraction of MMA to the formulation has a profound effect on particle morphology: It is possible that the main effect of MMA is to promote homogeneous nucleation. Table 3 shows the values of $N_{\mathrm{p}} / N_{\mathrm{d}}$ for the four latexes. It can be seen that the number of particles is lower than the number of miniemulsion droplets for the standard acrylic latexes, but the number is higher for the hybrids. The cause of this difference was the lower stability of the standard acrylic miniemulsions as compared to the hybrid miniemulsions (due to the effect of PU in reducing the Ostwald ripening effect $\left.{ }^{59}\right)$. Figure 8 shows that $\mathrm{d}(B) / \mathrm{d} t$ values from backscattering measurements are approximately an order of magnitude lower for the hybrid latex, indicating its greater stability. Marginally stable miniemulsions are prone to suffer droplet-droplet and droplet-particle coalescence leading to the number of particles being smaller than the number of the original miniemulsion droplets ${ }^{60}$.

In the case of the stable hybrid miniemulsions, the number of polymer particles was higher than that of the miniemulsion droplets, the effect being more noticeable in the presence of MMA. This indicates that a fraction of the polymer particles was formed by homogeneous nucleation and that MMA enhanced this process. Homogeneous nucleation requires the presence of water-soluble monomers. However, highly water-soluble monomers, such as HEMA and MAA, lead - in the absence of moderately water-soluble monomers - to the formation of water-soluble polymers that do not precipitate to produce new particles. Moderately water-soluble monomers, such as MMA, impart hydrophobicity to the polymer produced in the aqueous phase, thus allowing its precipitation to form new particles by homogeneous nucleation.

Table 3. $\mathrm{N}_{\mathrm{p}} / \mathrm{N}_{\mathrm{d}}$ values for the standard acrylic and the hybrid latexes.

\begin{tabular}{cc}
\hline Latex & $\mathrm{N}_{\mathrm{p}} / \mathrm{N}_{\mathrm{d}}$ \\
\hline S-MMA0 & 0.7 \\
S-MMA1 & 0.6
\end{tabular}


Published in Langmuir (2011) 27(7) pp 3878-3888

$\begin{array}{ll}\text { H-MMA0 } & 1.2 \\ \text { H-MMA1 } & 1.6\end{array}$

(a)

(b)

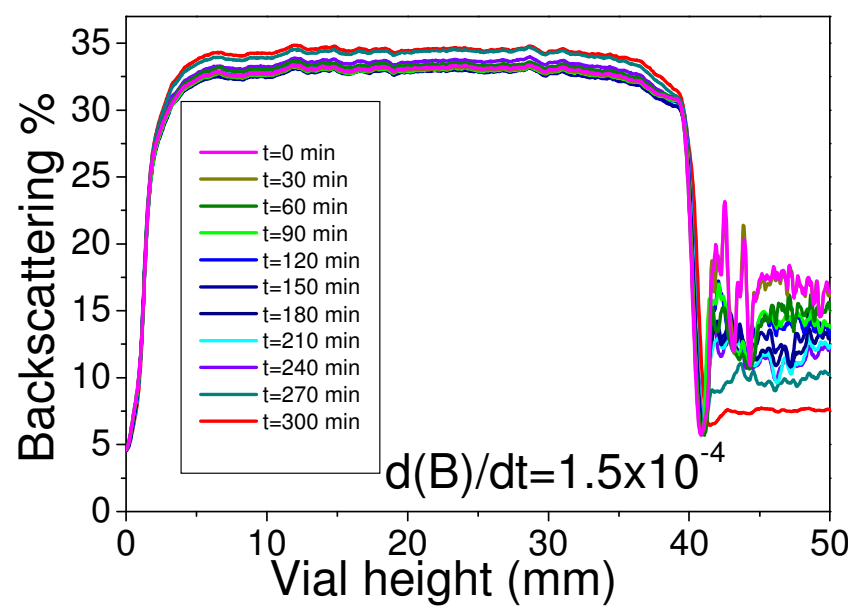

(c)

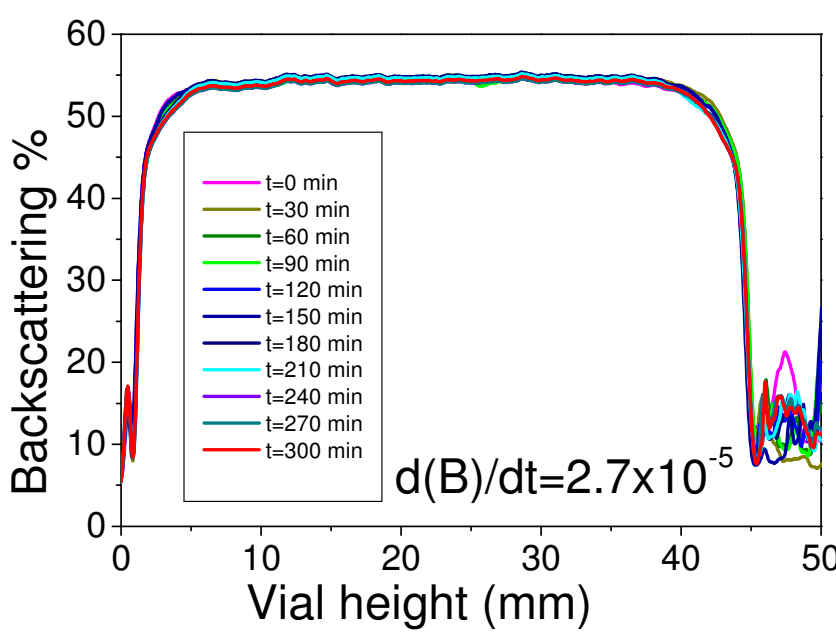

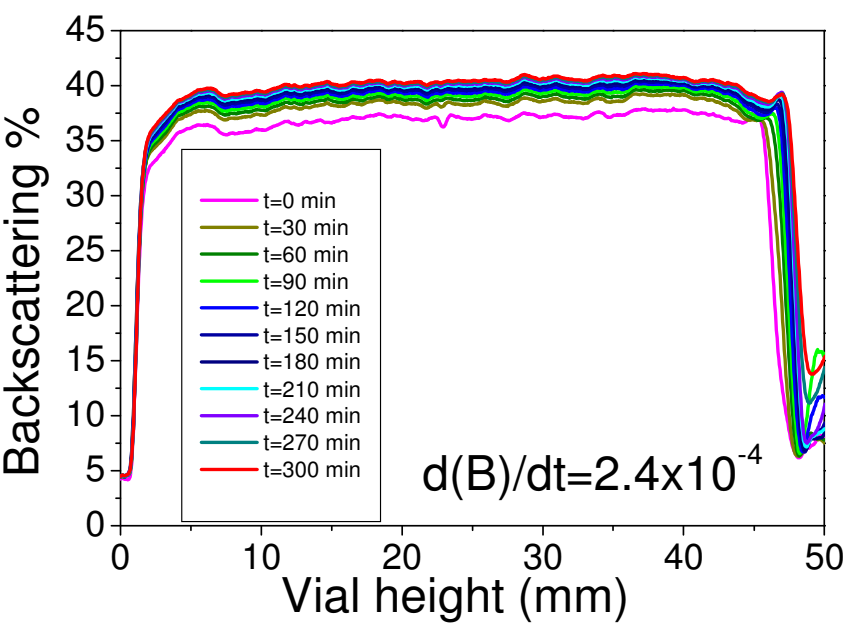

(d)

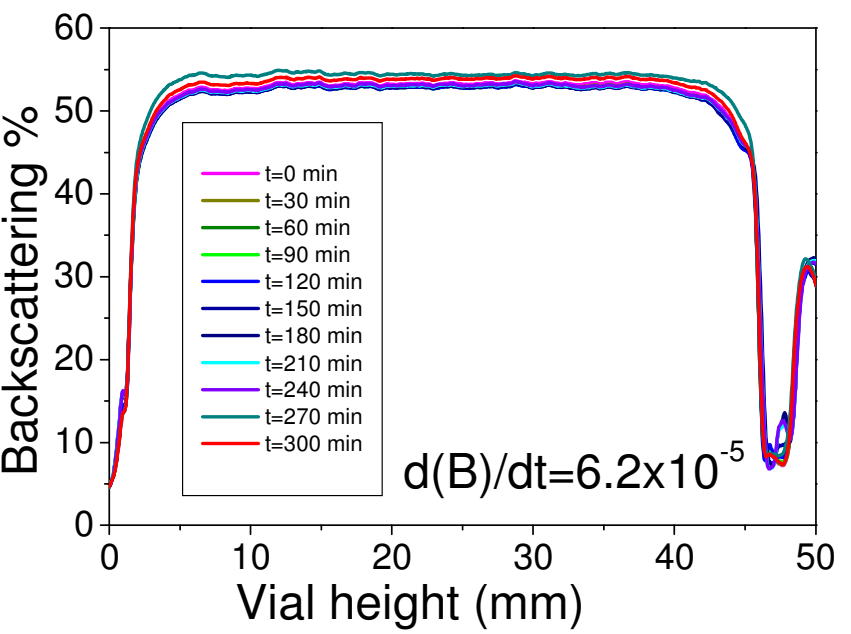

Figure 8. Backscattering data obtained over the times indicated at $30{ }^{\circ} \mathrm{C}$ to provide information on colloidal stability of the four miniemulsions: (a) S-MMA0 ; (b) S-MMA1; (c) H-MMA0; (d) HMMA1. Values of $d(B) / d t$ are stated for each set of data.

The more extended homogeneous nucleation promoted by MMA in the hybrid latex will create particles formed only by (meth)acrylic monomers, which correspond to the small, rather uniform 
particles shown in Figure 7. These particles should also contain HEMA, which can be easily transported to these particles through the aqueous phase, as it is rather water-soluble. However, the water-insoluble PU will remain in the droplets. Therefore, the miniemulsion droplets will contain a relatively low fraction of HEMA and a relatively high fraction of PU. In addition, bisphenol A and 2EHA, which have very low water-solubilities of $0.12 \mathrm{~g} / \mathrm{L}^{[61]}$ and $0.1 \mathrm{~g} / \mathrm{L}^{[62]}$, respectively, as well as SA, which is almost completely water insoluble, will also remain in the miniemulsion droplets and particles.

The relatively high concentration of both PU and BPA and the relatively low concentration of HEMA will affect the type of gel formed. In comparison with the case in which the composition of the droplets is equal to that of the formulation, the acrylic chains are shorter (because the effect of BPA as a chain transfer agent) and contain a lower fraction of HEMA units. On the other hand, the PU chains are longer because of the chain extension with BPA. As a consequence, a loosely crosslinked network was formed, which allowed some degree of phase separation.

The polymer formed in the particles resulting from homogeneous nucleation was an acrylic copolymer in which the gel was formed by intermolecular chain transfer to polymer followed by a termination by combination ${ }^{55}$.

\subsection{Macro-scale Adhesive and Mechanical Properties}

The adhesive properties of the standard compositions and the hybrids are considered next. Table 4 shows the values for the holding power shear test at three different temperatures. The shear resistance increased remarkably when PU was added to the formulations. In fact, the hybrid PSAs did not fail at a temperature of $30{ }^{\circ} \mathrm{C}$ over a 7-week period, whereas the corresponding acrylic PSAs failed in $c a .30$ minutes or less. This is a striking difference, and it demonstrates a very useful characteristic of the hybrid PSAs. Moreover, differences in failure mechanisms were observed macroscopically, as standard acrylic PSAs presented a cohesive failure, whereas hybrid systems had 
an adhesive failure. The increased failure times are attributed to an increase in the cohesive strength of the film caused by the introduction of PU. The greater shear holding power of the hybrids, in comparison to the standard acrylics, correlates with their higher gel content (Figure 3) and crosslinking density.

Table 4. Values for holding power shear test failure times at three different temperatures

\begin{tabular}{cccc}
\hline $\begin{array}{c}\text { Latex } \\
\text { name }\end{array}$ & $\begin{array}{c}\mathrm{T}=30^{\circ} \mathrm{C} \text { failure time } \\
\text { (min.) }\end{array}$ & $\begin{array}{c}\mathrm{T}=70^{\circ} \mathrm{C} \text { failure time } \\
\text { (min.) }\end{array}$ & $\begin{array}{c}\mathrm{T}=100^{\circ} \mathrm{C} \text { failure time } \\
\text { (min.) }\end{array}$ \\
\hline S-MMA0 & $31.8 \pm 4.2$ & $4.7 \pm 2.3$ & $5.2 \pm 4.4$ \\
S-MMA1 & $20.4 \pm 6.6$ & $33.0 \pm 8.5$ & $5.5 \pm 4.5$ \\
H-MMA0 & $70,560 *$ & $211.2 \pm 60.6$ & $12.8 \pm 5.1$ \\
H-MMA1 & $70,560 *$ & $158.8 \pm 25.4$ & $19.9 \pm 5.1$
\end{tabular}

*Experiment stopped after 7 weeks without failure.

Probe-tack experiments were performed on each type of latex PSA at a debonding velocity of $V_{\text {deb }}$ $=100 \mu \mathrm{m} \mathrm{s}^{-1}$. Figure 9 compares representative results for the latex with and without MMA. As is clearly shown, the maximum stress, the maximum deformation, and the stress of the plateau are almost equivalent in these experiments with an initial debonding rate of $1 \mathrm{~s}^{-1}$. In the case of the film without MMA (S-MMA0), the plateau finishes more abruptly with a more abrupt detachment. This is the detachment associated with a slightly more elastic character. Nevertheless, the differences between the two adhesives are within the reproducibility range of the probe-tack test, and therefore there is no significant effect of the MMA addition on the tack behaviour of the standard acrylic film. 


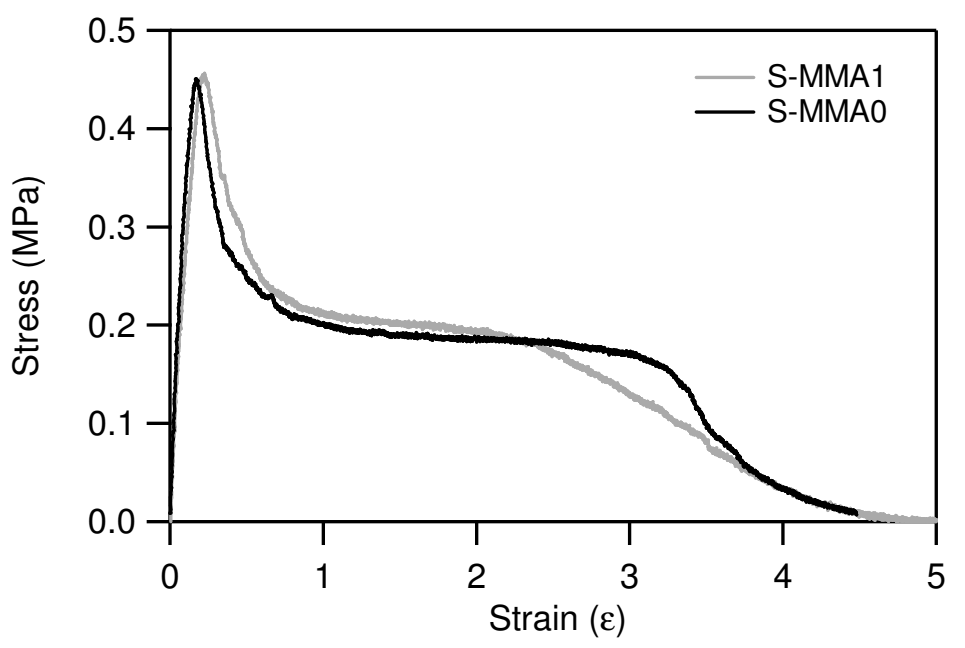

Figure 9. A representative stress-strain curve obtained from probe-tack experiment on standard acrylic formulations S-MMA0 and S-MMA1, without and with MMA, respectively. $V_{\mathrm{deb}}=100$ $\mu \mathrm{m} / \mathrm{s}$.

The rheological properties, at small deformations, were determined for the same two latexes to aid in the interpretation of the adhesive properties. Figure 10 shows that the presence of MMA in the copolymer (S-MMA1), increases slightly both the elastic and the loss moduli.

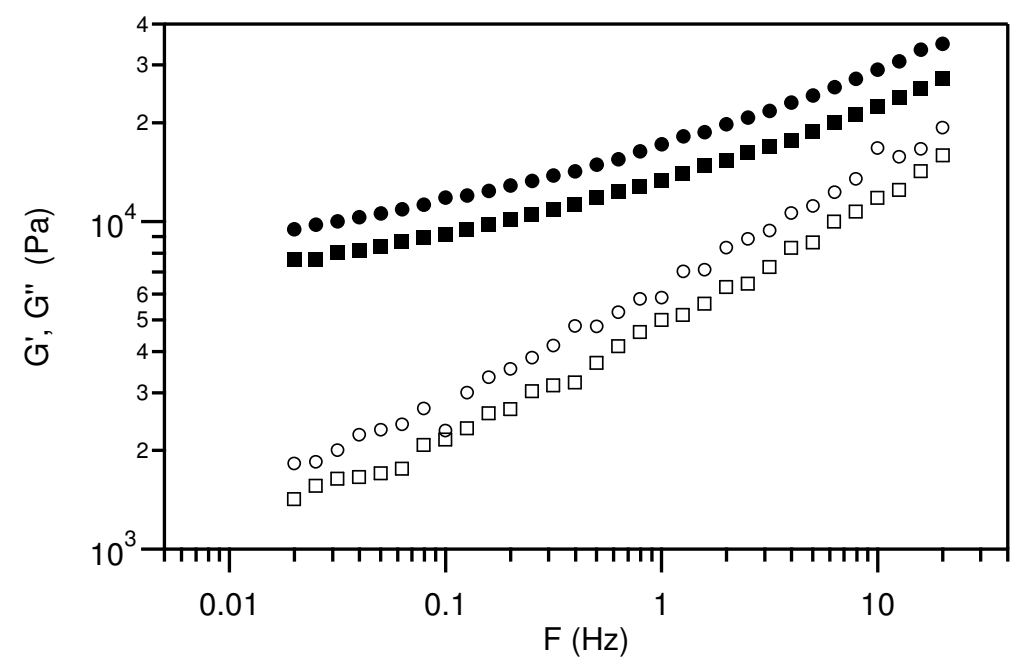

Figure 10. Frequency dependence of the elastic and loss moduli for a deformation of $8 \%$. The filled symbols correspond to $G^{\prime}$ and the open symbols to $G^{\prime}$. Squares ( $\square$ and $\square$ ) represent S-MMA0 (without MMA) and circles $(\bullet$ and $\circ)$ represent S-MMA1 (with MMA). 
The effect of incorporating PU into the two acrylic formulations can be determined from the results on H-MMA0 and H-MMA1. Comparisons between the probe-tack curves for the acrylic and hybrid latex are presented in Figures 11 and 12.

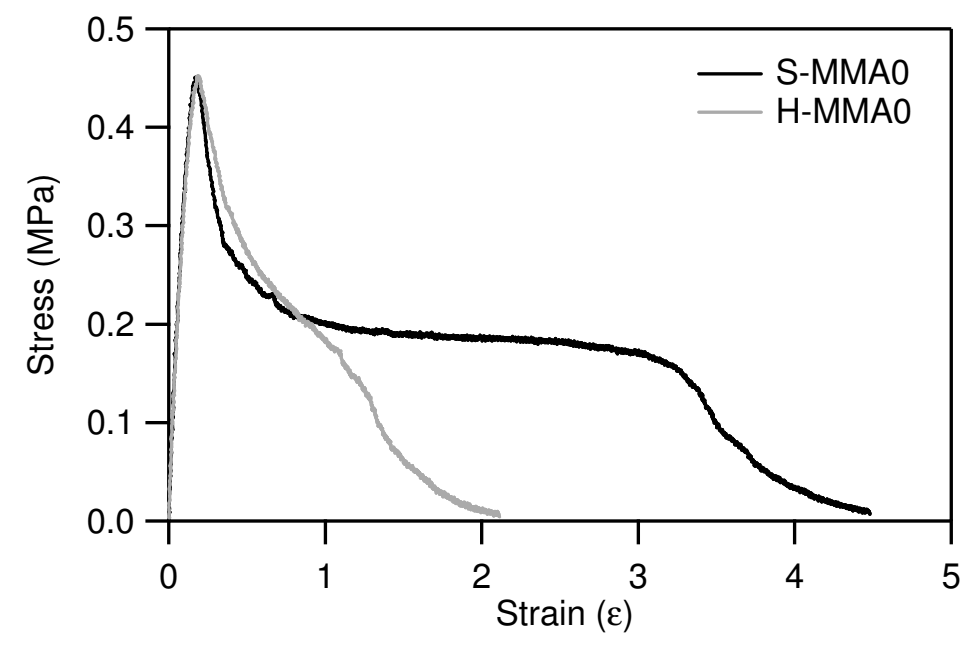

Figure 11. Representative stress-strain curves obtained from probe-tack experiment on S-MMA0 and H-MMA0. $\mathrm{V}_{\mathrm{deb}}=100 \mu \mathrm{m} / \mathrm{s}$

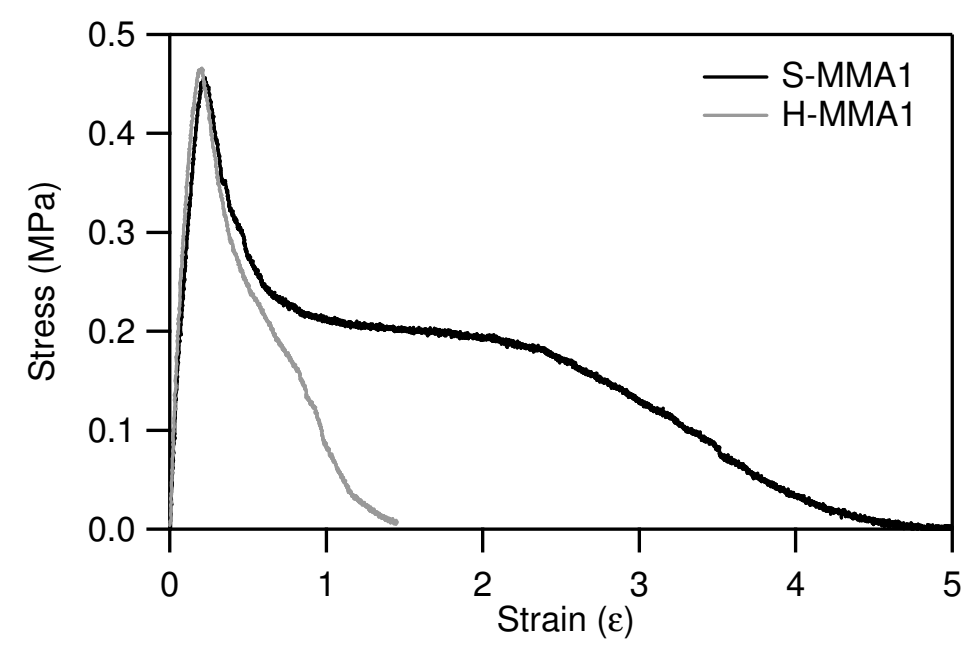

Figure 12. Representative stress-strain curves obtained from probe-tack experiment on S-MMA1 and H-MMA1. $\mathrm{V}_{\mathrm{deb}}=100 \mu \mathrm{m} / \mathrm{s}$. 
As seen on Figures 11 and 12 and in Table 5, with and without MMA in the copolymer, a very large decrease in the maximum deformation of the adhesive layer before detachment is observed with the addition of PU into the formulation, and there is a corresponding decrease in the adhesion energy. This trend can be attributed to the higher elasticity of the hybrid systems, resulting from their greater gel fraction and crosslinking density. The results of the swelling measurements of the gel fraction, $Q$, as given in Table 2, are qualitatively consistent with the measurements of modulus, $G$, presented in Figure 13 and 14, because in a good solvent $G \sim \mathrm{Q}^{-2} \cdot{ }^{[63]}$ More quantitative comparisons are difficult to make due to the presence of MMA, which also modifies the glass transition temperature of the polymer.

The tack results are readily explained by bulk rheological measurements (Figures 13 and 14). Both types of hybrid present significantly higher storage and loss moduli in the rheological measurements (Figures 13 and 14) in comparison to the standard acrylic. Deplace et al. ${ }^{38}$ have explained that high tack adhesion requires that the energy dissipation (represented by the loss modulus) is high relative to the elastic (storage) modulus. A long fibrillation plateau in the probetack experiment correlates with macroscopic properties in which the ratio $G{ }^{\prime \prime} / G^{, 2}$ is high. At the same time, a PSA must fulfill the Dahlquist criterion, which stipulates that the material is not too solid-like: $G^{\prime}$ at $1 \mathrm{~Hz}$ must be less than $0.1 \mathrm{MPa}^{38,64}$.

The results in Figures 13 and 14 reveal that the polymers, with and without PU, are not too solid-like. Although the addition of PU raises $G^{\prime}$, the level is not too high to violate the Dahlquist criterion. On the other hand, the ratio of $G^{\prime \prime}$ to $G^{\prime 2}$ is lower for the hybrids in comparison to the corresponding acrylic copolymers. For instance, at a frequency of $1 \mathrm{~Hz}$, the value of $G^{\prime \prime} / G^{\prime 2}$ is 2.8 $\mathrm{x} 10^{-5} \mathrm{~Pa}^{-1}$ for S-MMA0, but it falls to $0.7 \times 10^{-5} \mathrm{~Pa}^{-1}$ for H-MMA0. Thus, it is found that the addition of PU raises the storage modulus $\left(G^{\prime}\right)$ to bring the material closer to the Dahlquist criterion. Yet because the loss modulus $\left(G^{\prime \prime}\right)$ is not raised in proportion, the tack adhesion energy decreases. This result is not desirable for adhesive applications. 


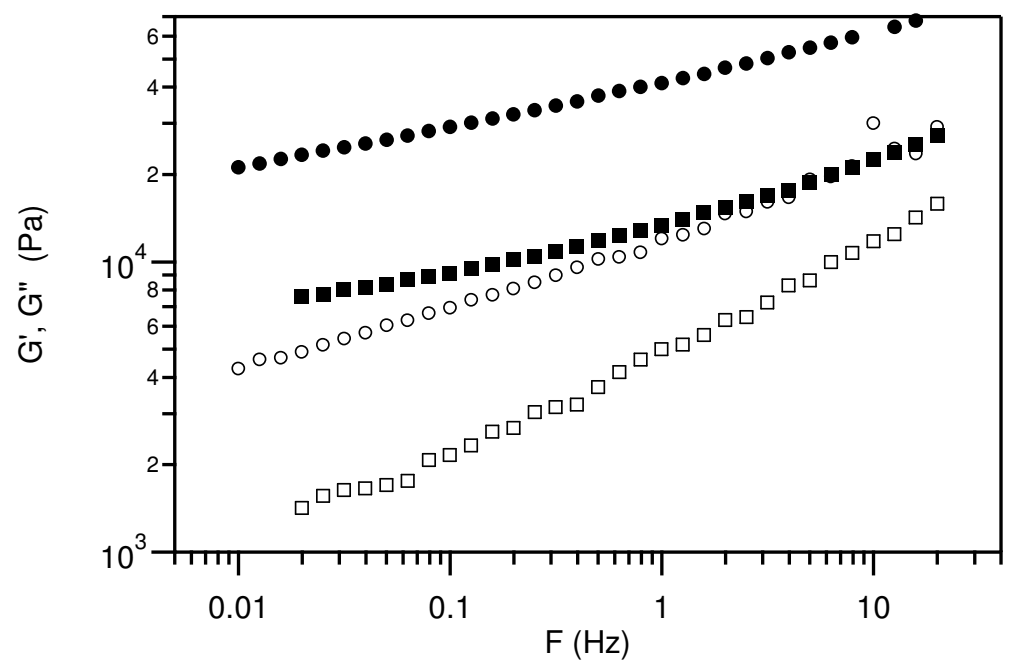

Figure 13. Rheological properties of latexes formulated without MMA. Filled symbols correspond to $G^{\prime}$ and open symbols correspond to $G^{\prime}$. Squares ( $\square$ and $\square$ ) represent the standard acrylic (SMMA0) and circles (• and ○) represent the corresponding hybrid (H-MMA0).

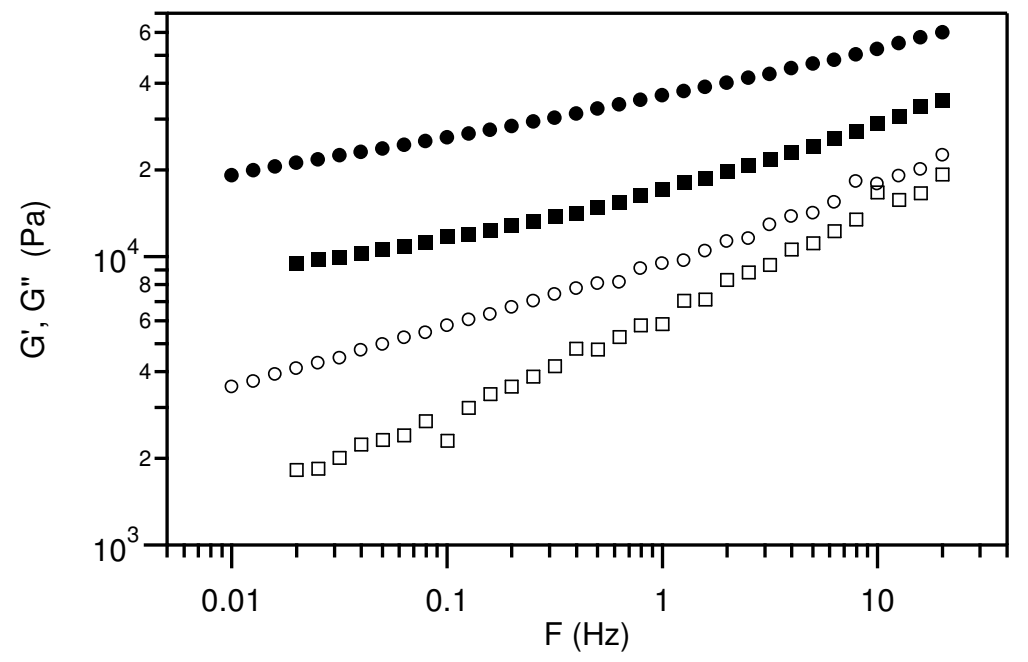

Figure 14. Rheological properties of latexes formulated with MMA. Filled symbols correspond to $G^{\prime}$ and open symbols correspond to $G^{\prime}$. Squares ( $\square$ and $\square$ ) represent the standard acrylic (SMMA1) and circles $(\bullet$ and $\circ)$ represent the corresponding hybrid (H-MMA1).

\subsection{Nano-scale Adhesion Characteristics}

The probe-tack data for the standard latex in Figures 11 and 12 show plateau regions that are characteristic of cavitation and fibrillation de-bonding mechanisms. When PU is incorporated into 
the formulations, the extent of deformation of the adhesive is substantially decreased, and the plateaux are significantly shorter. These results from investigation at the macro-scale can be compared to nano-scale measurements using AFM.

Crosby et al. ${ }^{65}$ have previously considered the deformation and failure modes in soft adhesives in confinement. They explained how the initial deformation of an elastic adhesive layer is governed by a geometrical parameter (the confinement ratio), a bulk material parameter (the tensile elastic modulus, $E$ ), and an interfacial parameter, $\mathcal{G}_{\mathrm{c}}$ (the critical energy release rate). The confinement ratio is defined as the radius of contacting probe, $a$, divided by the adhesive layer thickness, $h$. The specific values of these parameters determine the operative regime on a deformation map.

In an AFM force spectroscopy experiment, the radius of contact, $a$, between the probe and the adhesive surface (considering some indentation) is on the order of $100 \mathrm{~nm}$. The films used in the AFM experiments had a thickness, $h$, of approximately $10 \mu \mathrm{m}$. Hence the confinement ratio is given as $a / h=10^{-2}$. If we estimate that $\mathcal{G}_{\mathrm{c}}=0.1 \mathrm{Jm}^{-2}$, and use an experimental value of $E=10^{5} \mathrm{~Pa}$, we find that $\mathcal{G}_{\mathrm{c}} / E a=10$. This is a relatively high value of this parameter, which corresponds on the deformation map to the regime of bulk failure through cavitation and fibrillation of the polymer ${ }^{65}$. In the macro-scale experiments, by comparison, the confinement ratio is must greater, but bulk failure is likewise expected, even though the value of $\mathcal{G}_{\mathrm{c}} / E a$ is lower. It is therefore reasonable to expect some correspondence between the probe-tack and the AFM force spectroscopy results, as is indeed the case in the results presented hereafter. Note that whereas the AFM phase images are indicative of viscous dissipation at small strains (in the linear regime), the force spectroscopy experiments are sensitive to non-linear elastic properties at high strain.

The extension of the polymer during adhesive de-bonding is considered through measurements of $d_{\max }$ obtained from force spectroscopy. This measurement is analogous to the strain at failure in the macro-scale probe-tack measurements. Figure 15 shows the distributions of the measured $d_{\max }$ values for the four different latex compositions. The mean values are listed in Table 5. The effect of 
PU incorporation is apparent. For compositions with and without MMA, the $d_{\max }$ values obtained for the standard acrylic (S-MMA0 and S-MMA1) are significantly greater than what is found for the corresponding hybrid (H-MMA0 and H-MMA1). The greater extension at the nano-scale can be explained by fibrillation of the polymer during the force spectroscopy experiment. Comparing the distributions of $d_{\max }$ for S-MMA1 and H-MMA1, it is seen that there is broader distribution for the hybrid, which corresponds to greater heterogeneity at the nano-scale (Figure 7).

Table 5 shows that the decrease in the amount of extension prior to adhesive failure for the PU hybrids (i.e. comparing the $\mathrm{S}$ and $\mathrm{H}$ materials), observed here at the nano-scale in $d_{\max }$, is consistent with the results obtained in macro-scale measurements of $\varepsilon_{\max }$ (see also Figures 11 and 12). Values for the standard adhesive are greater than the values for the corresponding hybrid, which can be explained by the effect of the PU in stiffening the polymer too much. The AFM tip indents to a depth on the order of $500 \mathrm{~nm}$, so that a $d_{\max }$ of $2.4 \mu \mathrm{m}$ for S-MMA1 corresponds to a deformation ratio of 4.8, which is equal to the observed macro-scale strain at failure, $\varepsilon_{\max }$, in this case. The quantitative agreement between $d_{\max }$ and $\varepsilon_{\max }$ is poorer in the case of S-MMA0, H-MMA0 and H-MMA1, but nevertheless PU addition is seen to decrease $d_{\max }$ for both of the hybrid materials when comparing to the standard material, just as $\varepsilon_{\max }$ was likewise seen to decrease.

Furthermore, Table 5 shows that the lowest adhesion energy $\left(W_{\text {adh }}\right)$ and the lowest nano-scale adhesion energy $(\gamma)$ are observed for H-MMA1. There is likewise a qualitative correspondence between $W_{\text {adh }}$ and $\gamma$ in that S-MMA1 $>$ S-MMA0 for both. However, there is a disagreement for the hybrid latex without MMA (H-MMA0), for which the nano-scale $\gamma$ is relatively large, but the macroscale $W_{\text {adh }}$ is relatively low. At the nano-scale, the addition of the PU into the hybrid decreases $d_{\max }$ but not as severely as is observed in the macro-scale deformation. Furthermore, the maximum stress attained in the force spectroscopy measurements is not significantly reduced in the hybrid, and a greater force is required for extension. Consequently, the value of $\gamma$ is not reduced significantly in 
Published in Langmuir (2011) 27(7) pp 3878-3888

the H-MMA0 hybrid compared to the standard latex S-MMA0. At the macro-scale for S-MMA0, on the other hand, there is a very short fibrillation plateau and a corresponding low $W_{\text {adh }}$.

Table 5. Nano-scale mechanical property measurements of the standard and hybrid latexes compared to macro-scale adhesive properties

\begin{tabular}{ccccc}
\hline Latex & Mean $d_{\max }(\mu \mathrm{m})$ & $\varepsilon_{\max }$ & $\begin{array}{c}\text { Mean } \gamma \\
\left(10^{-15} \mathrm{~J}\right)\end{array}$ & $\mathrm{W}_{\text {adh }}\left(\mathrm{J} / \mathrm{m}^{2}\right)$ \\
\hline S-MMA0 & 3.3 & $4.2 \pm 0.4$ & 217 & $73.7 \pm 1.3$ \\
H-MMA0 & 2.4 & $2.1 \pm 0.3$ & 354 & $38.6 \pm 5.1$ \\
S-MMA1 & 2.4 & $4.8 \pm 0.6$ & 347 & $82.9 \pm 13.6$ \\
H-MMA1 & 1.2 & $1.5 \pm 0.2$ & 36 & $29.5 \pm 5.2$
\end{tabular}


(a)

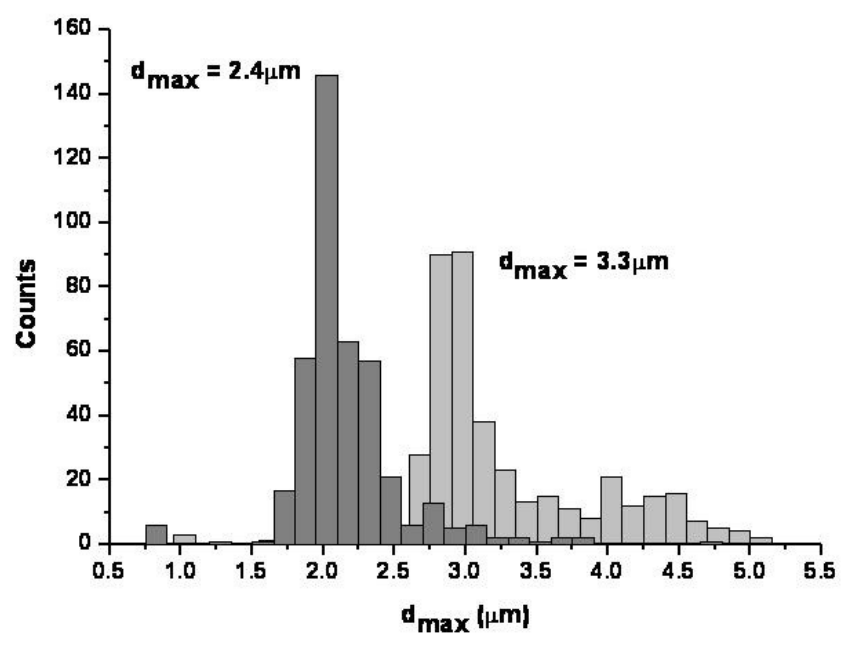

(b)

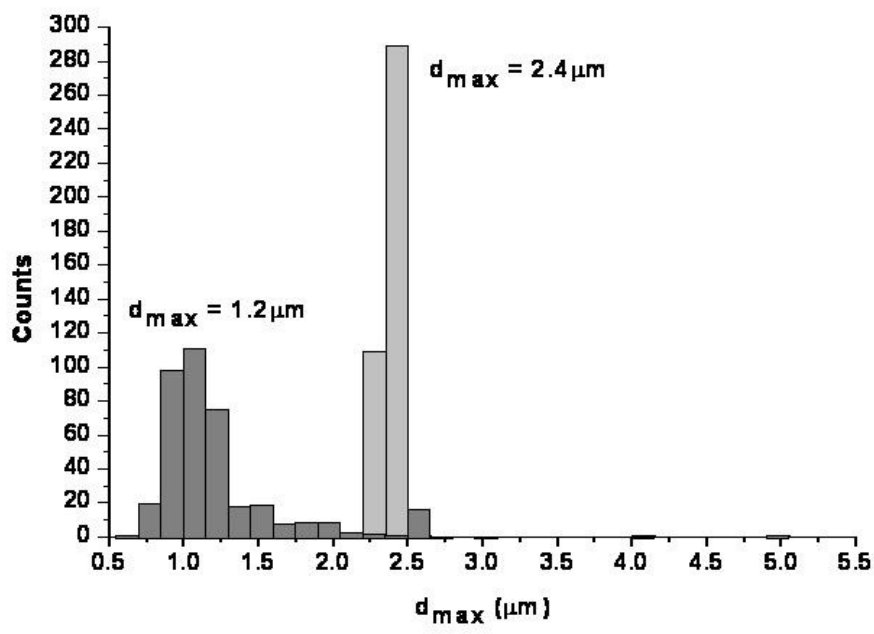

Figure 15. Histograms of the statistical distribution of $d_{\max }$ obtained from AFM force spectroscopy experiments, showing the effect of PU incorporation. (a) Latex without MMA: S-MMA0 (light gray bars) and H-MMA0 (dark gray bars); (b) Latex containing MMA: S-MMA1 (light gray bars) and HMMA1 (dark gray bars). The bin width for both (a) and (b) histograms is $0.15 \mu \mathrm{m}$.

\section{Conclusions}

Polyurethane/acrylic hybrid waterborne PSAs were synthesized by a one-step miniemulsion polymerization process, where both polyaddition and free radical polymerization reactions occurred 
Published in Langmuir (2011) 27(7) pp 3878-3888

simultaneously. The extent of the incorporation of the polyurethane into the acrylic backbone was followed via the gel content development.

With the addition of MMA to the acrylic, individual particles showed an uneven distribution of PU in the particles, whereas the particles were more homogeneous in the absence of MMA. This heterogeneous distribution of the PU is probably the result of nucleation mechanisms other than droplet nucleation that occurred during the polymerization. The hemispherical particle morphology is attributed to phase separation between acrylic-rich and PU-rich phases.

The shear resistance was substantially raised when PU was incorporated in the acrylic network, indicating an increase in film cohesion. However, the higher gel content and concomitant higher elasticity of the hybrid networks containing PU lead to a significant decrease in tack, which is usually less desirable for applications as PSAs. A decrease in the extensibility of the polymer upon the addition of PU was found both at the macro-scale and at the nano-scale. Further materials development is required to achieve a balance between the elastic and viscous properties in order to achieve a higher shear holding power combined with an acceptable level of tack adhesion.

\section{Acknowledgments}

A.L. acknowledges the financial support of the Basque Government ("Ikertzaileen Prestakuntza eta Hobekuntza Programak"). The financial support of the European Commission (NAPOLEON NMP3-CT-2005-011844) is gratefully acknowledged. 


\section{References}

(1) Nabuurs, T.; Baijards, R. A.; German, A. L., Prog. Org. Coat. 1996, 27, 163-172.

(2) Wang, S. T.; Schork, F. J.; Poehlein, G. W.; Gooch, J. W., J. Appl. Pol. Sci. 1996, 60, 20692076.

(3) Wu, X. Q.; Schork, F. J.; Gooch, J. W., J. Polym. Sci., Part A: Polym. Chem. 1999, 37, 41594168.

(4) Liu, Y.; Farwaha, R.; Shih, F. EP 933384, 1999.

(5) De Wet-Roos, D.; Knoetze, J. H.; Cooray, B.; Sanderson, R. D., J. Appl. Pol. Sci. 1999, 71, 1347-1360.

(6) Kawahara, H.; Goto, T.; Ohnishi, K.; Ogura, H.; Kage, H.; Matsuno, Y., J. Appl. Pol. Sci. 2001, 81, 128-133.

(7) Stumbe, J. F.; Calderara, F.; Riess, G., Polym. Bull. 2001, 47, 277-282.

(8) Wu, L.; You, B.; Li, D., J. Appl. Pol. Sci. 2002, 84, 1620-1628.

(9) Pan, G.; Wu, L.; Zhang, Z.; Li, D., J. Appl. Pol. Sci. 2002, 83, 1736-1743.

(10) Wang, C.; Chu, F.; Graillat, C.; Guyot, A., Polymer React. Eng. 2003, 11, 541-562.

(11) Wang, C.; Chu, F.; Graillat, C.; Guyot, A.; Gauthier, C., Polym. Adv. Technol. 2005, 16, 139145.

(12) Wang, C.; Chu, F.; Jin, L.; Lin, M.; Xu, Y.; Guyot, A., Polym. Adv. Technol. 2009, 20, 319326.

(13) Li, D.; Daniels, E. S.; Dimonie, V.; Sudol, E. D.; El-Aasser, M. S., Macromolecules 2005, $38,4183-4192$.

(14) Landfester, K.; Pawelzik, U.; Antonietti, M., Polymer 2005, 46, 9892-9898.

(15) Aznar, A. C.; Pardini, O. R.; Amalvy, J. I., Prog. Org. Coat. 2006, 55, 43-49. 
(16) Canetta, E.; Marchal, J.; Lei, C. H.; Deplace, F.; Köning, A.; Creton, C.; Ouzineb, K.; Keddie, J. L., Langmuir 2009, 25, 11021-11031.

(17) Guo, J. S. WO 2008083991, 2008.

(18) Donkus, J. L., Adhesives Age 1997, 40, 32-37.

(19) Gerin, P. A.; Grohens, Y.; ;, S. R.; Holl, Y., J. Adhes. Sci. Technol. 1999, 13, 217-236.

(20) Tobing, S. D.; Klein, A., J. Appl. Polym. Sci. 2001, 79, 2230-2244.

(21) Zosel, A. J. Adhes. 1994, 44, 1-16.

(22) Zosel, A. Colloid Polym. Sci, 1985, 263, 541-553.

(23) Deplace, F.; Carelli, C.; Langenfeld, A.; Rabjohns, M. A.; Foster, A. B.; Lovell, P. A.; Creton, C., ACS Appl. Mater. Interfaces, 2009, 1, 2021-2029

(24) Deplace, F.; Rabjohns, M. A.; Yamaguchi, T.; Foster, A. B.; Carelli, C.; Lei, C.-H.; Ouzineb, K.; Keddie, J. L.; Lovell, P. A.; Creton, C., Soft Matter, 2009, 5, 1440-1447.

(25) Bellamine, A.; Degrandi, E.; Gerst, M.; Stark, R.; Beyers, C.; Creton, C. Macromol. Mater.Eng. In press.(26) Hirose, M.; Kadowaki, F.; Zhou, J., Prog. Org. Coat. 1997, 31, (1-2), 157-169.

(27) Hirose, M. Z., J.; Nagai, K., Prog. Org. Coat. 2000, 38, 27-34.

(28) Landfester, K.; Tiarks, F.; Hentze, H.; Antonietti, M., Macromol. Chem. Phys. 2000, 201, 15.

(29) Tiarks, F.; K.; L.; Antonietti, M., J. Polym. Sci., Part A: Polym. Chem. 2001, 39, 2520-2524.

(30) Barrère, M.; Landfester, K., Macromolecules 2003, 36, 5119-5125.

(31) Scott, M.; Bhushan, B., Ultramicroscopy 2003, 97, 151-169.

(32) Anczykowski, B.; Gotsmann, B.; Fuchs, H.; Cleveland, J. P.; Elings, V. B., Appl. Surf. Sci. 1999, 140, 376-382.

(33) Lei, C.; Ouzineb, K.; Dupont, O.; Keddie, J. L., J. Coll. Interf. Sci. 2007, 307, 56-63.

(34) Mallégol, J.; Dupont, O.; Keddie, J. L., Langmuir 2001, 17, 7022-7031. 
Published in Langmuir (2011) 27(7) pp 3878-3888

(35) FTM 8. Resistance to shear from a standard surface. In FINAT Technical Handbook, 7th ed.; FINAT: The Hague, 2005.

(36) Lakrout, H. S., P.; Creton, C., J. Adhesion 1999, 69, (3-4), 307-359.

(37) Chiche, A.; Dollhofer, J.; Creton, C., Eur. Phys. J. E 2005, 17, 389-401.

(38) Deplace, F.; Carelli, C.; Mariot, S.; Retsos, H.; Chateauminois, A.; Ouzineb, K.; Creton, C., J. Adhes. 2009, 85, 18-54.

(39) Portigliatti, M.; Koutsos, V.; Herve, H.; Léger, L., Langmuir 2000, 16, 6374-6376.

(40) Paiva, A.; Sheller, N.; Forter, M. D.; Crosby, A. J.; Shull, K. R., Macromolecules 2000, 33, 1878-1881.

(41) Paiva, A.; Sheller, N.; Foster, M. D.; Crosby, A. J.; Shull, K. R., Macromolecules 2001, 34, 2269-2276.

(42) Moon, S.; Foster, M. D., Langmuir 2002, 18, 1865-1871.

(43) Benmouna, F.; Dimitrova, T. D.; Johannsmann, D., Langmuir 2003, 19, 10247-10253.

(44) Moon, S.; Swearingen, S.; Foster, M. D., Polymer 2004, 45, 5951-5959.

(45) Wang, T.; Canetta, E.; Weerakkody, T. G.; Keddie, J. L., ACS Appl. Mater. Interfaces 2009, $1,631-639$.

(46) Lopez, A.; Chemtob, A.; Milton, J. L.; Manea, M.; Paulis, M.; Barandiaran, M. J.; Theisinger, S.; Landfester, K.; Hergeth, W. D.; Udagama, R.; McKenna, T.; Simal, F.; Asua, J. M., Ind. Eng. Chem. Res. 2008, 47, 6289-6297.

(47) van Hamersveld, E. M. S.; van Es, J. J. G. S.; Cuperus, F. P., Colloids Surf., A 1999, 153, 285-296.

(48) Tsavalas, J. G.; Gooch, J. W.; Schork, F. J., J. Appl. Polym. Sci. 2000, 75, 916-927.

(49) Gooch, J. W.; Dong, H.; Schork, J. F., J. Appl. Polym. Sci. 2000, 76, 105-114.

(50) Tsavalas, J. G.; Luo, Y.; Hudda, L.; Schork, F. J., Polymer React. Eng. 2003, 11, 277-304.

(51) Hudda, L.; Tsavalas, J. G.; Schork, F. J., Polymer 2005, 46, 993-1001. 
Published in Langmuir (2011) 27(7) pp 3878-3888

(52) Rodriguez, R.; Barandiaran, M. J.; Asua, J. M., Polymer 2008, 49, 691-696.

(53) Kadoma, Y.; Fujisawa, S., Biomaterials 2000, 21, (21), 2125-2130.

(54) Kong, L.; Wang, L.-F.; Zhang, H.-Y., THEOCHEM 2005, 716, (1-3), $27-31$.

(55) Plessis, C.; Arzamendi, G.; Alberdi, J. M.; Agnely, M.; Leiza, J. R.; Asua, J. M., Macromolecules 2001, 34, 6138-6143.

(56) Lopez, A.; Degrandi, E.; Creton, C.; Asua, J. M., Submitted.

(57) Lau, A. W. C.; Portigliatti, M.; Raphaël, E.; Léger, L. Europhys. Lett., 2002, 60, 717-723.

(58) Wu, S. Polymer Interface and Adhesion, Marcel Dekker, Inc.: New York, 1982, p. 366.

(59) Asua, J. M., Prog. Polym. Sci., 2002, 27, 1283-1346.

(60) Rodriguez, R.; Barandiaran, M. J.; Asua, J. M., Macromolecules, 2007, 40, 5735-5742.

(61) Li, J-H.; Zhou, B-X.; Cai, W-M., J. Chem. Eng. Data, 2007, 52, 2511-2513.

(62) Yeliseyeva, V. I. In Emulsion Polymerization; Piirma, I., Ed.; Academic Press: New York, $1982 ; \mathrm{p} 247$.

(63) Patel, S. K.; Malon, S.; Cohen, C.; Gillmor, J. R.; Colby, R. H., Macromolecules, 1992, 25, $5241-5251$.

(64) Dahlquist, C. A., Pressure-sensitive Adhesives. In Treatise on Adhesion and Adhesives, Patrick, R. L., Ed. Marcel Dekker, Inc.: New York, 1969; Vol. 2, pp 219-260.

(65) Crosby, A. J.; Shull, K. R.; Lakrout, H.; Creton, C., J. Appl. Phys. 2000, 88, 2956-2966. 


\section{For Table of Contents Only}
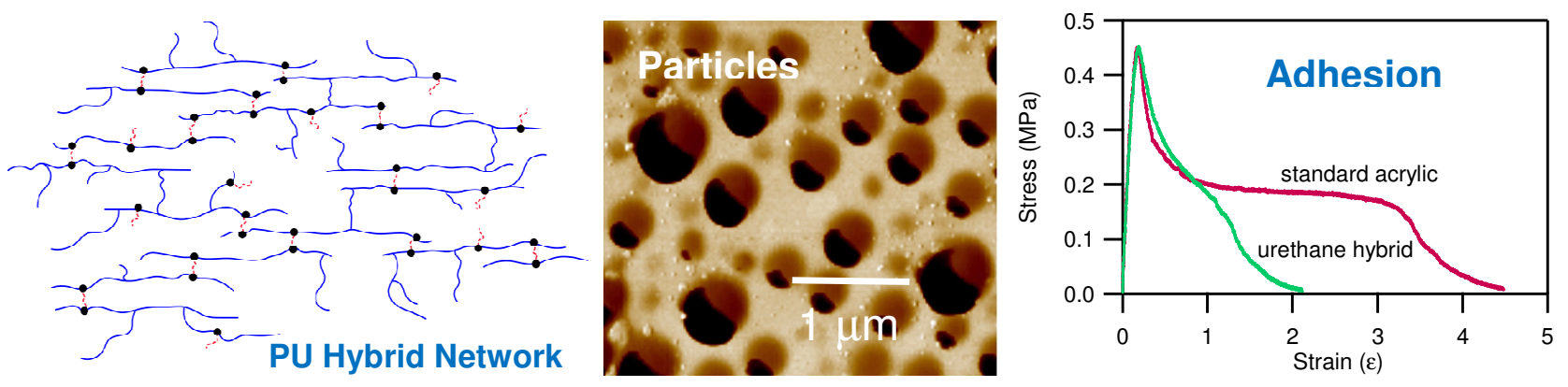